\title{
Towards an operative use of remote sensing for exploring the past using satellite data: The case study of Hierapolis (Turkey)
}

\author{
Rosa Lasaponara ${ }^{\mathrm{a}, \mathrm{d}, *}$, Giovanni Leucci ${ }^{\mathrm{b}}$, Nicola Masini ${ }^{\mathrm{c}}$, Raffaele Persico ${ }^{\mathrm{b}}$, Giuseppe Scardozzi ${ }^{\mathrm{b}}$ \\ a CNR-IMAA, C. da S. Loya, Tito, PZ, Italy \\ b CNR-IBAM, Lecce, Italy \\ c CNR-IBAM, C. da S. Loya, Tito, PZ, Italy \\ d Key Laboratory of Digital Earth Science, Institute of Remote Sensing and Digital Earth, Chinese Academy of Sciences, Beijing, 100094, China
}

\section{A R T I C L E I N F O}

\section{Article history:}

Received 27 November 2014

Received in revised form 10 December 2015

Accepted 11 December 2015

Available online $\mathrm{xxxx}$

\section{Keywords:}

Satellite remote sensing

Archaeological landscape

Ground penetrating radar

Magnetometry

Feature extraction

Hierapolis

Turkey

\begin{abstract}
A B S T R A C T
This paper is focused on the presentation and discussion of an object oriented approach, applied to the Hierapolis (Turkey) site, to automatically detect the subtle features linked to buried archaeological remains. The data processing is applied twice: (i) first, globally at the whole image and, (ii) second, at the significant subsets identified by global analysis, in order to refine the previously obtained categorization. Object oriented approaches are usually based on two main steps: i) first the segmentation, ii) then the classification. Herein, we first performed the unsupervised classification step and, then, the segmentation. This choice is given by the specificity of archaeological issue, in particular: (i) the subtle features/targets to be identified are partially or totally unknown and characterized by a very small spectral separability from the background, and therefore (ii) the discrimination between archaeological class and substrates likely suffers significant confusion. To cope with these issues, the first step is based on an unsupervised classification, which provides a first 'rough' categorization of pixels; the second step, based on the segmentation, enables us to extract the geometric shape, and, in turn, to only categorize as archaeological class those pixels belonging to geometrically (rectangular and linear) shaped clusters. Outputs from this classification identify rectangular and linear features of archaeological interest whose size suggested that they may be a farm and some sectors of an aqueduct, respectively. Results from satellite based analysis were successfully evaluated by georadar and geomagnetic prospection along with field survey. From georadar and geomagnetic prospection we were able i) to confirm the presence of buried remains and ii) to detail and characterize these archaeological features at the subsoil level as well as to define the local stratigraphy. From field survey we dated the detected buried remains to a period spanning from Imperial Roman to early Byzantine historical times.
\end{abstract}

(c) 2015 Elsevier Inc. All rights reserved.

\section{Introduction}

In the last decade, the study of landscape has become increasingly important and significant for a number of disciplines, including earth sciences, ecology, anthropology, historical geography, archaeology, etc. Thus it enhances various challenges and needs related to the sustainable management, protection, and preservation issues including the safeguard of the archaeological records and traces of past settlement dynamics still fossilized in the modern landscape. In particular, archaeological remains are not renewable resources that must be preserved because they provide the only available source of information about people and civilizations that flourished in the distant past. Specific legislations are generally adopted throughout the world to preserve

\footnotetext{
* Corresponding author at: CNR-IMAA, C. da S. Loya, Tito, PZ, Italy.

E-mail addresses: rosa.lasaponara@imaa.cnr.it (R. Lasaponara), g.leucci@ibam.cnr.it (G. Leucci), n.masini@ibam.cnr.it (N. Masini),r.persico@ibam.cnr.it (R. Persico), g.scardozzi@ibam.cnr.it (G. Scardozzi).
}

archaeological remains and cultural landscape with specific limitations in planning and design processes. Cultural heritage preservation requires, as mandatory steps, a suitable knowledge and documentation. This is important: i) to support preventive archaeology aimed at orienting the design strategies of modern infrastructures and buildings, ii) to help the decision makers in urban planning in areas and regions rich in cultural resources, and iii) to plan time consuming and expensive archaeological excavations.

Currently, archaeological investigations are based on the survey and study of traces and evidence left by human civilizations over time. In operative contexts, knowledge of the human past is generally achieved by using documentary sources and field surveys carried out to detect superficial remains such as pottery, stone fragments and other objects of ancient material culture. Nevertheless, it is important to consider that these materials are generally scattered over large surfaces due to erosion, washing, ploughing, flooding etc. They do not therefore always provide information on the presence of possible buried remains such as walls, graves, or pits associated with superficial ancient materials. 
Even if field surveys are necessary to assess the cultural value of a territory and to provide a rough dating, they are not sufficient, and it is well advised to back them up with additional investigations to obtain detailed spatial information on the subsurface remains and settlements.

Therefore, in many cases the main problem to be approached is the detection of buried archaeological structures not visible in situ. These structures can be identified by using sub-metric remotely sensed data able to detect changes in surface parameters due to the physical/chemical interactions between the archaeological deposits (masonry structures, ditches, etc.) and their neighbouring soils. These changes, related to vegetation coverage, humidity and organic material content, appear as subtle spatial discontinuities or variations in the reflectance values (i.e. tones or colours) of vegetation and soil surface (Agapiou \& Hadjimitsis, 2011; Beck, 2007; Crawford, 1929; Grøn et al., 2011;
Lasaponara \& Masini, 2007; Rowlands \& Sarris, 2007; Traviglia \& Cottica, 2011; Wilson, 1982).

Moreover, the visibility of these subtle traces, appearing as crop/ weed, soil and shadow marks, has a great intra- and inter year variability due to changes in crop types and phenology, soil moisture content and other surface parameters. This means that the visibility of archaeological marks may be profitably enhanced by multi-date observations. The identification of marks related to past human activities based on remote sensing can be improved by also taking into account additional characteristics, such as the geometric pattern of the target under investigation. In fact, traces relating to man-made structures and landscape transformations are usually identified by geometric or regular shapes depending on the historical period (such as a circle, or curvilinear shapes for Neolithic villages, regular meshes for Roman settlements,

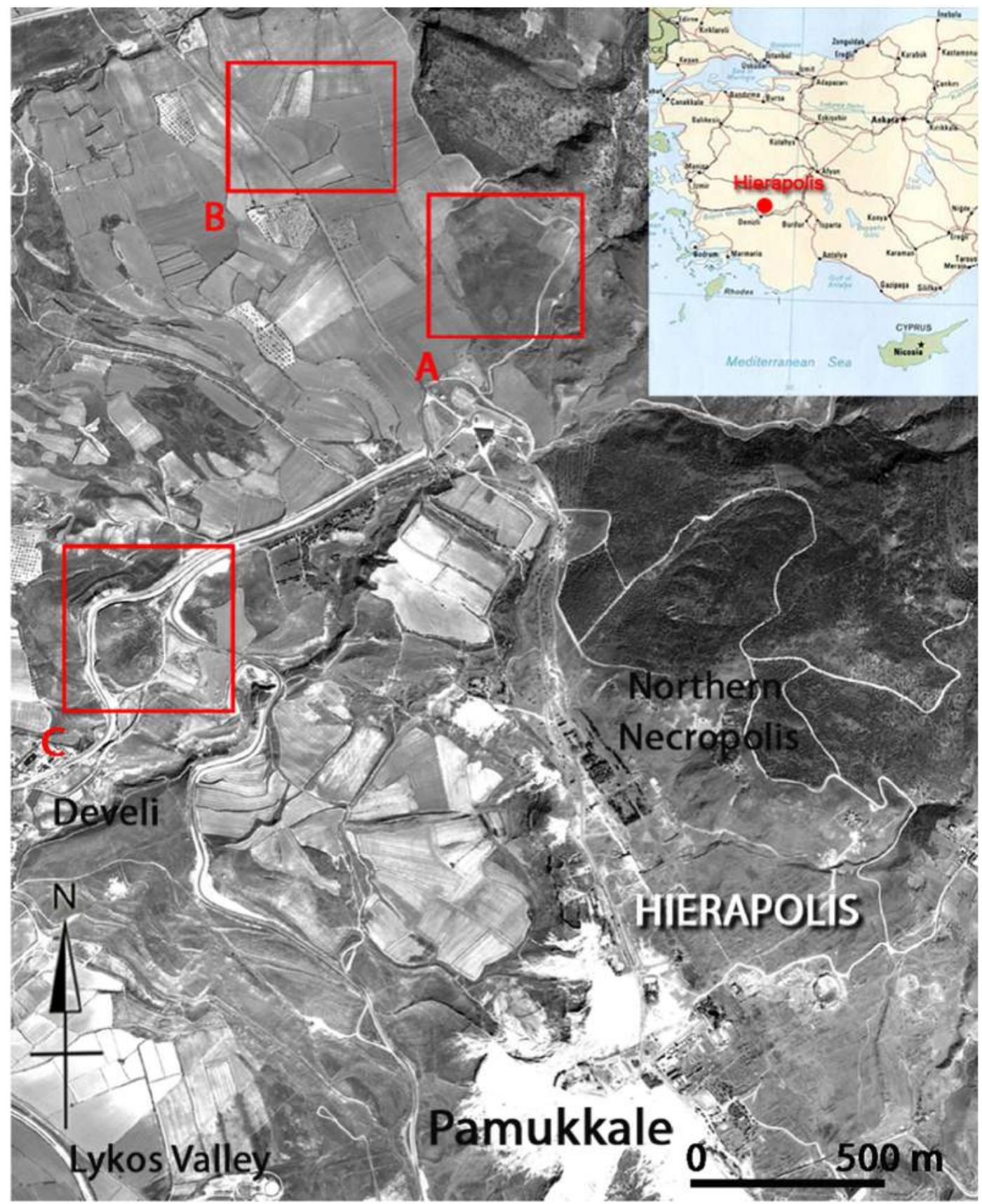

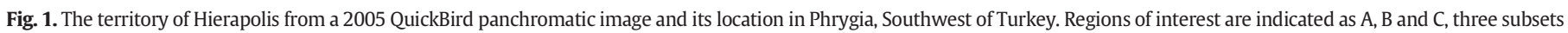
whose results will be shown in the following figures and discussed in the text. 
etc.) or by the function of the structures (roads, aqueducts, drainage, field divisions, etc.).

The availability of multispectral sub-metric remotely sensed data provides new opportunities to improve the extraction of information, from the qualitative and quantitative point of view, and also in the case of subtle signals which typically characterize buried and shallow archaeological remains.

Nevertheless, in the archaeological operative practise the use of remote sensing is still underexploited and, in particular, reduced to a mere visual interpretation exercise. Up to now, investigations have been mainly based on approaches aimed at enhancing archaeological features using spectral indices, RGB composition, principal component analysis, Tasselet Cup transformation, and edge detection (Argote-Espino \& Chavez, 2005; Garrison et al., 2008; Lasaponara \& Masini, 2006; Traviglia \& Cottica, 2011; for a more complete bibliography see Lasaponara \& Masini, 2012).

A few investigations have been addressed to the extraction of information using automatic or semiautomatic tools as, for example, De Laet, Paulissen, and Waelkens (2007) who compared the performance obtained from the application of pixel based and object based classification (using eCognition tools), edge enhancement and visual interpretation for a test site in Turkey, which was characterized by the presence of emerging scattered remains made up of quite big stones. On the basis of the results obtained the authors considered the visual interpretation better than the other considered approaches.

Trier, Larsen, and Solberg (2009) developed a satellite based automatic approach to extract circular crop/soil marks linked to buried features in Norway, but the rate of success was unsatisfactory.

Tarantino and Figorito (2014) and Figorito and Tarantino (2014) applied a supervised classification, and therefore a semi-automatic procedure, based on segmentation of historical aerial photographs.

D'Orazio, Palumbo, and Guaragnell (2012) proposed a semiautomatic approach based on an active contour model for the extraction of linear traces, related to ancient roads and roman centuriations.

Wonsok et al. (2013) applied a semiautomatic method based on the local orientation using genetic algorithm for the detection of circular marks related to ancient graves in the desert of Xinjiang (China).

Schuetter et al. (2013) proposed a semiautomatic approach for the detection of circular features related to ancient Arabian tombs.

Recently, Lasaponara, Leucci, Masini, and Persico (2014) successfully applied an unsupervised classification to satellite imagery, previously processed by using the LISA (Local Index of Spatial Autocorrelation), to extract circular traces of illegal excavations in Peru.
Luo et al. (2014) reliably extracted the circular archaeological tops of Qanat Shafts automatically from Google Earth Imagery by using a new method consisting of a combination of the circular Hough transform followed by mathematical morphological processing and the Canny edge detector.

This brief overview suggests that the reconnaissance of typical archaeological marks (such as crop, shadow, and soil/damp marks) by using remote sensing is quite complex and still less investigated with respect to other satellite traditional applications (as for example, vegetation, fire, geology, etc.). The complexity is not only due to the small signals that must be detected but also due to the greater variability of parameters that can influence their visibility and extraction.

The main goal of this paper is to assess the possibility of automatically extracting (by using unsupervised classifications) and mapping the subtle features/targets associated with archaeological buried remains. The study was carried out in the archaeological Greek/Roman/Byzantine site of Hierapolis (Turkey). It is a bare area, characterized by a significant presence of stones and scattered materials that make the investigation particularly complex (details are in Section 2). Moreover, as common in archaeological studies and also in our investigated area, the features associated with buried archaeological remains are partially or totally unknown and characterized by a very small spectral separability from the background. To cope with this issue, we applied data processing based on an object oriented approach that is applied twice: (i) first, globally at the whole image and, (ii) second, at the significant subsets in order to refine the previously obtained categorization. Moreover, the novelty of the proposed methodology is also in the following: object oriented approaches are usually based on two main steps: i) first the segmentation, ii) then the classification; herein, we firstly performed the unsupervised classification step and, then, the segmentation. The choice is given by the specificity of the archaeological issue. In particular: (i) the subtle features/targets to be identified are partially or totally unknown and characterized by a very small spectral separability from the background, and (ii) the discrimination between archaeological class and substrates likely suffers significant confusion. Therefore, to cope with these issues, the first step is based on unsupervised classification, which provides a first 'rough' categorization of pixels, and the second step is the segmentation which enables us to extract the geometric shape, and, in turn, to only categorize as archaeological class those pixels belonging to geometrical clusters.

This approach has two advantages: 1 ) it does not require knowing and assigning a priori pre-established statistical distribution of classes as in the case of supervised classifications; and 2) it allows us the

\section{SSI assessment for soil and shadow marks (Lasaponara et al. 2008)}

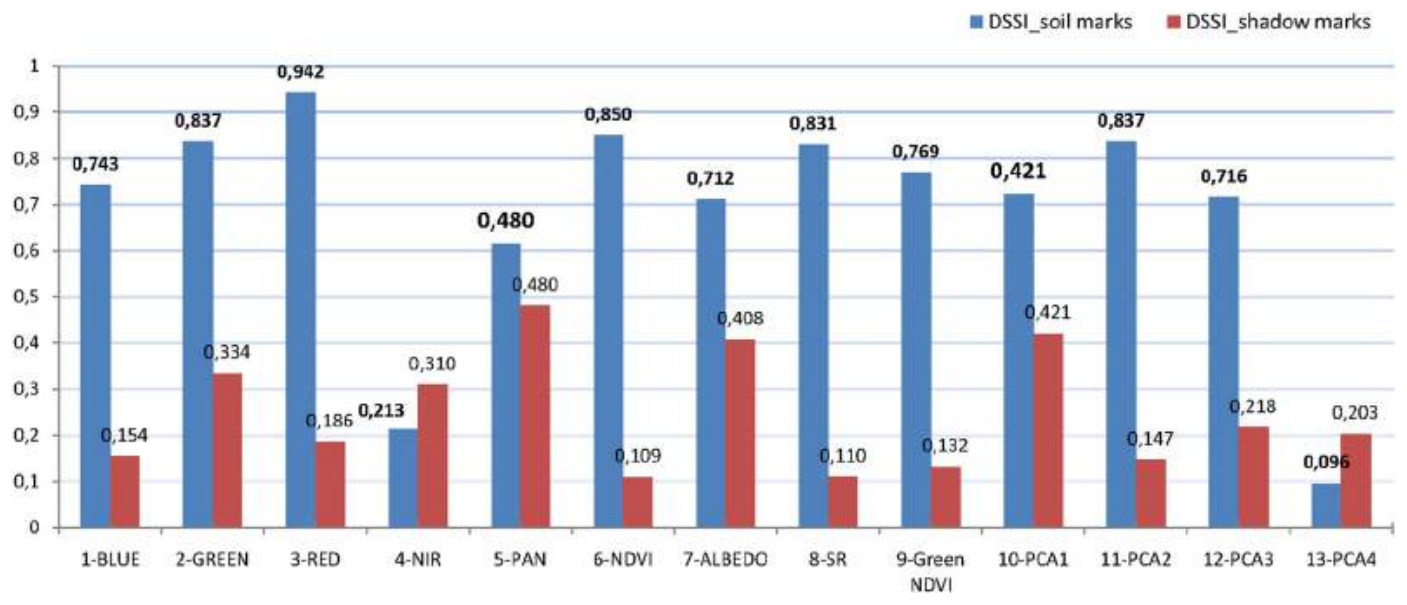

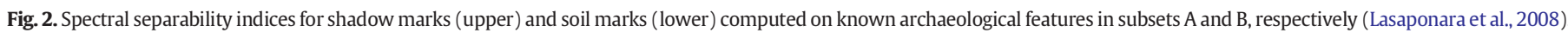
The indices have been computed for 2005 QuickBird data. 
identification and extraction of subtle signals/patterns, which exhibit a geometric shape, even if veiled, as in the case under investigation, by the presence of scattered building material (stone blocks, tiles, bricks).

Outputs of this classification procedure enable us to detect rectangular and linear features of archaeological interest whose size suggested that they may be a farm and some sectors of an aqueduct, respectively. The reliability of the results obtained from satellite data processing was evaluated by field surveys and geomagnetic and georadar prospections conducted in some sample areas. This paper, following the Copernicus (before GMES) recommendations, aims to provide an effort to make operative the use of satellite data, with particular reference to the adopted object oriented approach, in the framework of projects and activities of preventive archaeology.

\section{The context}

The above experimental approach was performed in the framework of the scientific activities of Missione Archeologica Italiana at Hierapolis (MAIER) which has been carrying out excavations, surveys and restorations since 1957 in Hierapolis in Turkey (see Fig. 1). The latter is on the
UNESCO World Heritage list and characterized by a rich archaeological heritage mainly comprising farms, roads and aqueducts spanning from the Hellenistic to the Byzantine period (300 BC-800 AD).

The archaeological investigations currently allowed the discovery of numerous archaeological remains, which are very important in the reconstruction of the ancient settlement pattern of the area, from the prehistoric to Ottoman times (D'Andria, Scardozzi, \& Spanò, 2008). MAIER's activities cover a large area, which is believed to have been under the control of the town. This concerns the eastern part of The Valley of the Lykos River, a tributary of the Meander (see Fig. 1, lower left), where Hierapolis lies, and a broad plateau to the north and north-east of the town, which Imperial Roman epigraphic documentation seems to indicate as belonging to Hierapolis (Scardozzi, 2011).

Systematic archaeological surveys improved the knowledge of the historical development of Hierapolis by means of the identification of many archaeological remains, such as quarries, aqueducts, roads, some ancient villages and rural farms (Scardozzi, 2012). The latter, which are the main focus of our investigations, span a period between late Hellenistic times and the early Byzantine period. In some cases the remains are quite well preserved, with walls in travertine blocks, and

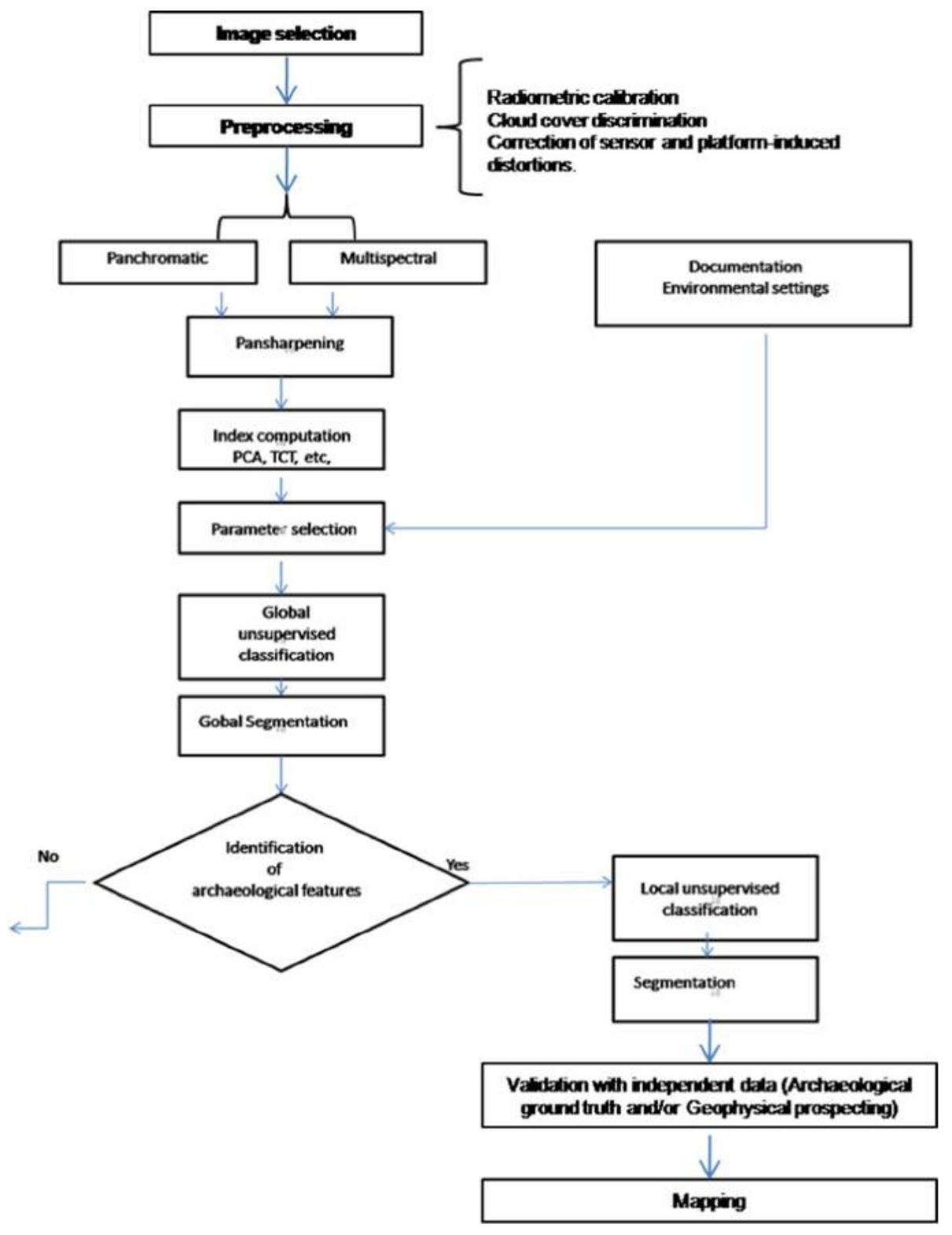

Fig. 3. Flowchart of the methodology for the satellite-based analyses. 
elements of installations for olive oil and wine production emerging, though sometimes the visible remains of these ancient farms are negligible.

In this context, the above said approach is being tried out in a large territory around Hierapolis ( $1400 \mathrm{Ha}$ ) with the purpose of making it useful for preventive archaeology and for the planning of future excavation campaigns. In particular, we considered three regions of interest (ROIs), named A, B and C (see Fig. 1), selected because past field survey campaigns put in evidence of the presence of superficial scattered materials of high archaeological interest.

Geophysical prospecting was also carried out on the anomalies of potential archaeological interest identified by remote sensing analyses on one of these ROIs ( $\mathrm{A}$ in Fig. 1). In particular geomagnetic and georadar techniques have been selected according to the dimensions of the areas of interest, the expected archaeological features and the need to provide 3D characterization of the geophysical anomalies.

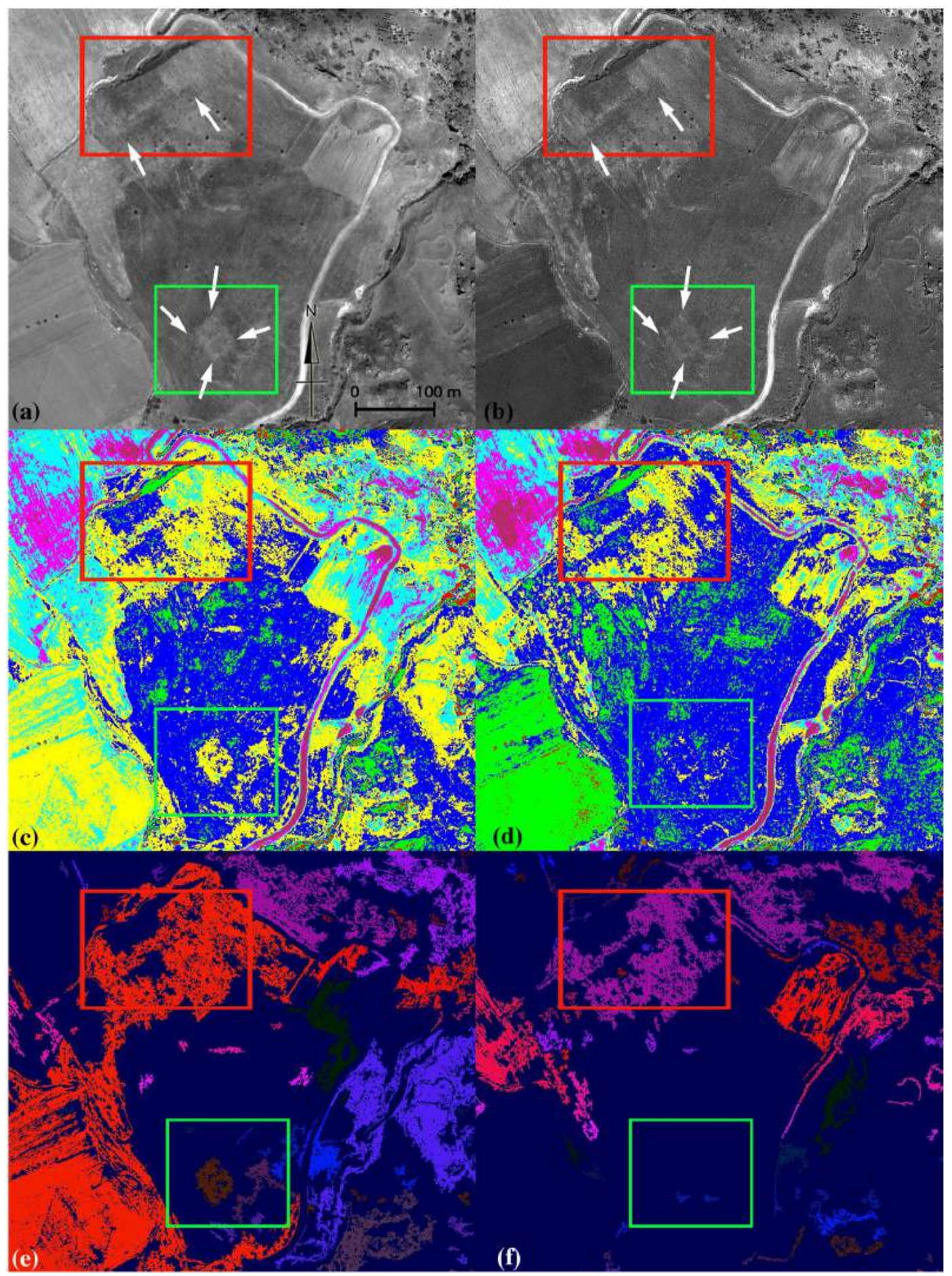

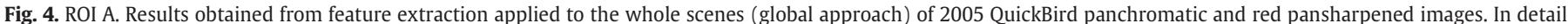

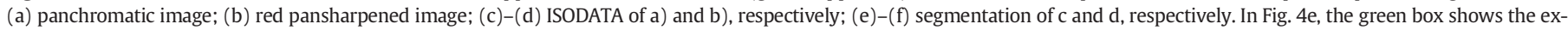

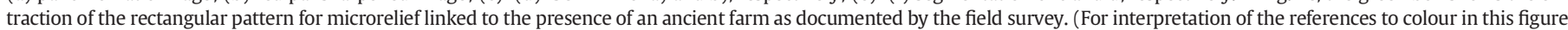
legend, the reader is referred to the web version of this article.) 


\section{Rational basis of the methodology}

Archaeological features (shadow-, soil- and crop-marks) can be described as geophysical and chemical spatial anomalies that tend to form geometric patterns according to the spatial morphology (structure and layout) of the exposed, buried and/or shallow archaeological remains. The different marks associated with the presence of archaeological remains can be detected using satellite images by exploiting specific spectral channels or their numerical combinations. In particular, the VHR satellite red channel has been found to be capable of revealing soil marks according to soil spectral signatures (Masini \& Lasaponara, 2006a), while the near-infrared (NIR) channel and vegetation indices are capable of enhancing crop-marks (Lasaponara \& Masini, 2007). Moreover, the capability of VHR satellite data to capture the presence of archaeological marks is strongly dependent on seasonal and data acquisition time. Satellite scenes acquired during early morning (as in the case of the QuickBird images used for this study) may be capable of capturing the shadows that occur only when the sun is low. The presence of micro-topographic reliefs should be much more evident in panchromatic, as can be seen in Hierapolis itself (Lasaponara, Masini, \& Scardozzi, 2008). The visibility of soil-marks depends on the soil properties and surface moisture content, and, consequently, on meteorological conditions especially prior to image acquisition. Finally, the crop-marks are strongly dependent on crop types and their phenology, as well as the

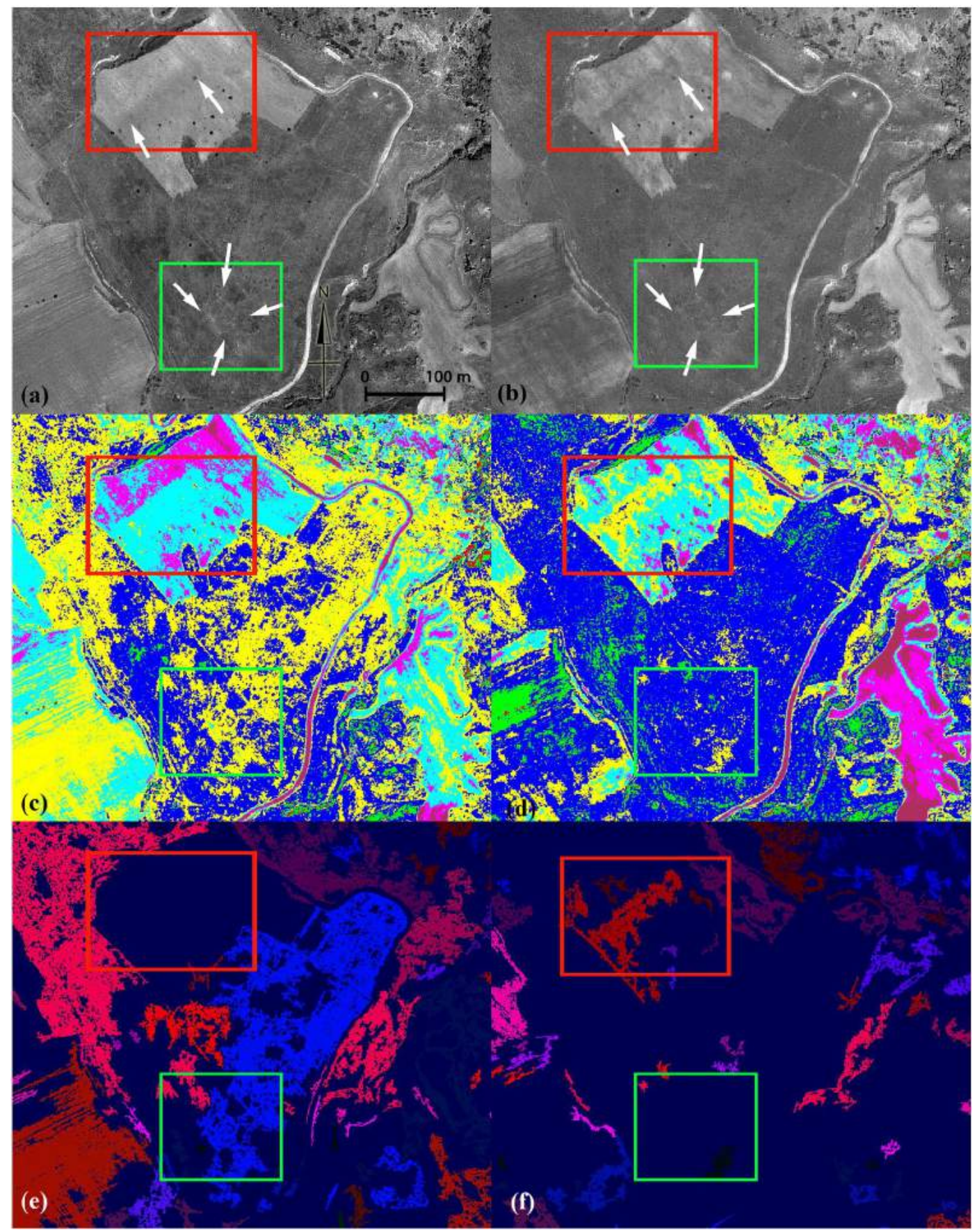

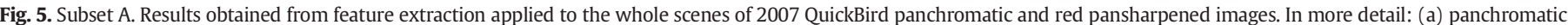

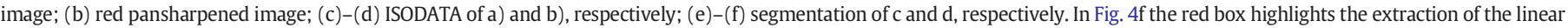

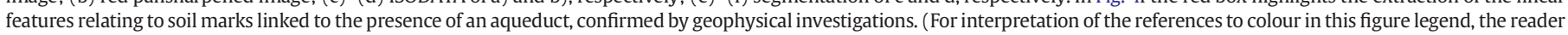
is referred to the web version of this article.) 
dynamics of meteorological variables and climate setting. This suggests that in some certain periods, the marks may be visible while at other times they are not. To cope with this issue, a multi temporal or multidate investigation (as done in this paper) can be useful.

For the current case study, we adopted a specific indicator (see formula 1), named spectral separability index (SSI) to assess the separability of the archaeological marks (Masini \& Lasaponara, 2006b).

$\mathrm{SSI}=\Delta \mu /(\sigma 1+\sigma 2)$

where $\Delta \mu$ and $\sigma 1+\sigma 2$ are respectively the average spectral differences and standard deviation observed for two masks, one for archaeological features and the second for their surroundings (Masini \& Lasaponara, 2006b).

In a previous investigation, conducted on the study area by Lasaponara et al. (2008), the SSI provided the numerical evaluation of the spectral separability of archaeological traces for some satellite products (panchromatic, image fused channels, the spectral indices, the principal component analysis (PCA), etc.)

Fig. 2 shows the values of the SSI obtained for previously investigated archaeological features in the current area. In particular: (i) soil marks were better distinguished by the red pansharpened product and (ii) shadow marks were better highlighted by the panchromatic image.

Similar findings were obtained not only for the study area (for previous investigations conducted in Turkey) but also in diverse geographic regions and for diverse archaeological features, for example in the Greek/Roman remains of Metapontum in the South of Italy (Masini \& Lasaponara, 2006a) or in desert areas of Peru (Masini, Lasaponara, \& Orefici, 2009).

\section{Data processing}

In this paper, an object-oriented approach is used for the extraction of archaeological features. It is based on the: (i) selection of the satellitebased parameters according to the surface covering (vegetation vs. bare surfaces) and the characteristics of the archaeological features, (ii) unsupervised classification of multi-date images and (iii) segmentation of results obtained from the classification. Steps (ii) and (iii) were applied twice: firstly at a global scale (namely at the whole image), and secondly at a local scale, centred on subsets identified from the global scale analysis, to refine the spatial characterization of features of archaeological interest.

The flowchart for satellite data processing is shown in Fig. 3.

On the basis of the results described in Section 3, for the current study a red data fusion product and panchromatic images were used.

The satellite data set used for this study is made up of two QuickBird images (panchromatic and multispectral bands), acquired with $0 \%$ percentage of cloud cover, on 25th March 2005 at 9:00 am and 10th April 2007 at 9:20 am, respectively. The two satellite images were purchased in standard product type. So they are geo-referenced and radiometrically calibrated, corrected for sensor and platform-induced distortions. This choice was due to the need to make general the applicability of the procedure we developed; considering that archaeological sites are often located in remote regions where no additional data are available for atmospheric correction.

Object oriented approaches are usually based on two main steps: i) first the segmentation, ii) then the classification. Herein, we firstly performed the unsupervised classification step and, then, the segmentation. The choice is given by the specificity of archaeological issue. In particular: (i) the subtle features/targets to be identified are partially or totally unknown and characterized by a very small spectral separability from the background, and (ii) the discrimination between archaeological class and substrates likely suffers significant confusion as clearly shown in Fig. 3. Therefore, to cope with these issues, the first step is based on the unsupervised classification, which provides a first 'rough' categorization of pixels, and the second step is the segmentation which enables the identification as archaeological class those pixels belonging to geometrically defined clusters.

\subsection{Unsupervised classification of satellite image}

Unsupervised classification requires limited human intervention in setting up the algorithm parameters. The importance of applying unsupervised classification in archaeological applications is that: (i) it is an automatic process, namely, it usually requires only a minimal amount of initial input compared with a supervised data processing; (ii) classes do not have to be defined a priori; and (iii) unknown feature classes may be discovered.

A number of unsupervised classification algorithms are commonly used in remote sensing, including (i) K-means clustering, and (ii) ISODATA (Iterative Self-Organizing Data Analysis Technique) (Ball \& Hall, 1965) which are quite similar. In both, the user has only to indicate (i) the number of predefined classes (clusters) and (ii) the number of iterations to be carried out. The only difference is that the K-means assumes that the number of clusters is known a priori whereas the ISODATA algorithm assigns the different number of clusters "dynamically". Both of these algorithms are iterative procedures, based on the following steps: (i) they first assign an arbitrary initial cluster vector, (ii) each pixel is classified to the closest cluster, and (iii) new cluster mean vectors are calculated based on all the pixels in one cluster. The second and third steps are iteratively repeated until the "variations" between the iteration is small. These variations can be computed and assessed in several different ways. For example, in the K-means algorithm, the cluster variability is optimized by a least square minimization of the cost function relating to Eq. (2).

$\operatorname{MSE}=\frac{\sum[\mathrm{x}-\mathrm{C}(\mathrm{x})]^{2}}{(\mathrm{~N}-\mathrm{c}) \mathrm{b}}$

where MSE is mean squared error, $\mathrm{N}$ is the number of pixels, $\mathrm{c}$ indicates the number of clusters, $b$ is the number of spectral bands, and $\mathrm{C}(\mathrm{x})$ is the mean value of the cluster that pixel $\mathrm{x}$ is assigned to.

Eq. (2) clearly shows that the minimization of MSE implies that Kmeans works best for spherical clusters that have the same variance. This indicates that the K-means algorithm tends to perform better for homogeneous surfaces/objects, as in particular desert areas.

The ISODATA algorithm will split a cluster in two, if the cluster's standard deviation exceeds a predefined limit and if the number of pixels is twice the minimum number threshold (Ball \& Hall, 1965).

ISODATA is considered more flexible compared to the K-means method, but it requires the empirical selection of many more parameters. For this reason, in this study we applied an ISODATA algorithm.

\subsection{Segmentation}

The unsupervised classification provides a new image made up of the identified classes which take into account the spectral information. The following segmentation reduces the complexity of the classification

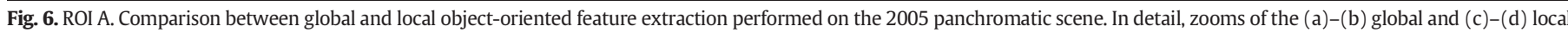

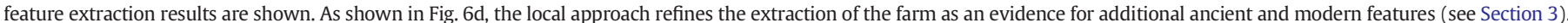

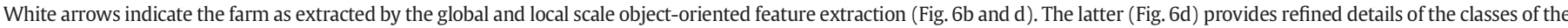

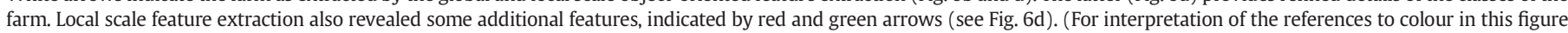
legend, the reader is referred to the web version of this article.) 

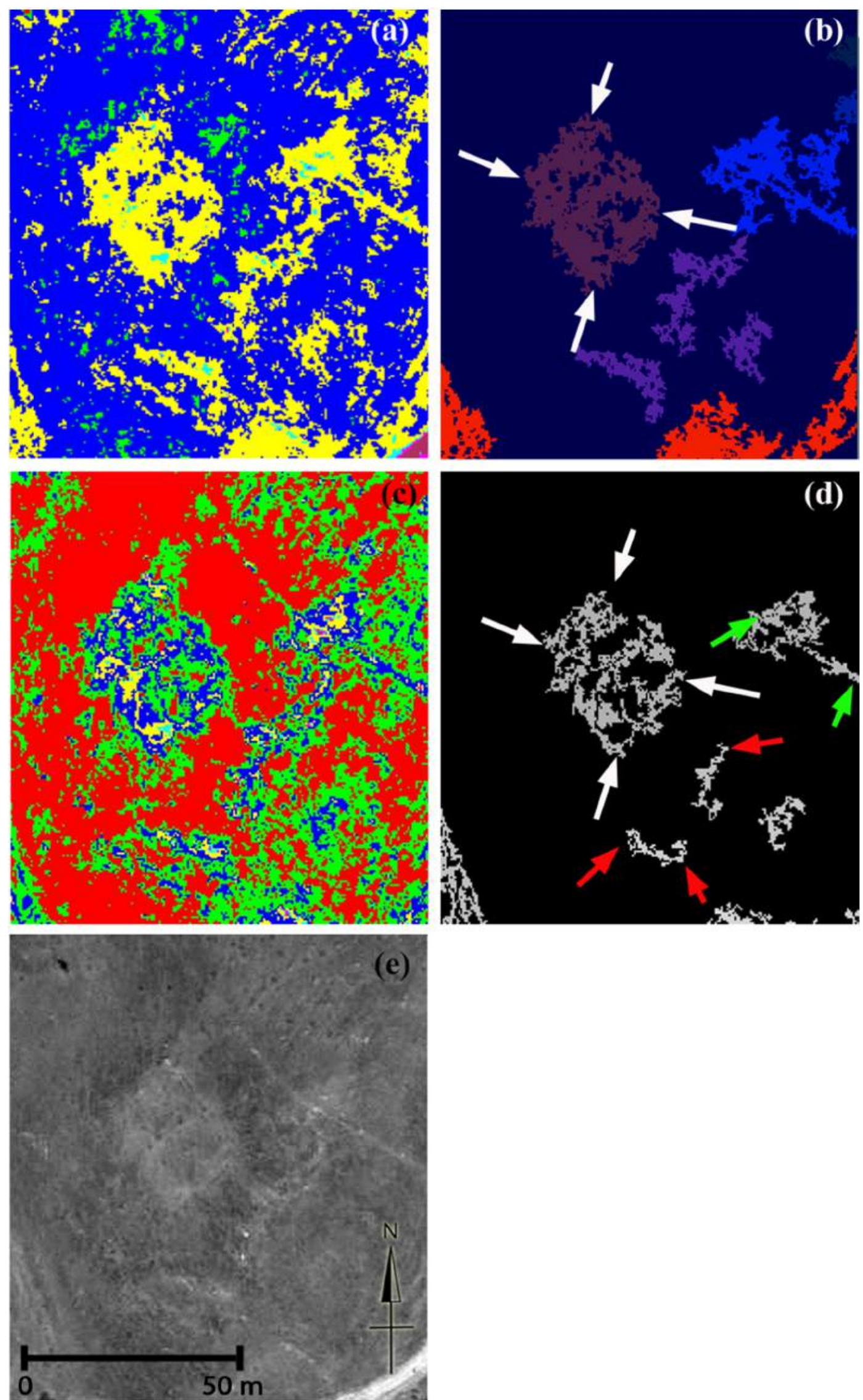

(e) 
Table 1

Statistics of Global ISODATA of 2005 panchromatic image for a subset including the farm and the aqueduct.

\begin{tabular}{|c|c|c|c|c|c|c|c|}
\hline Classes & Colour & Min & Max & Mean & Stdev & N. points & Note \\
\hline Class1 & & 119 & 386 & 340.75 & 42.67 & 222,285 & \\
\hline Class2 & & 352 & 421 & 387.15 & 6.03 & 151,867 & \\
\hline Class3 & & 384 & 458 & 407.83 & 6.07 & 149,900 & \\
\hline Class4 & & 406 & 450 & 429.98 & 6.3 & 174,461 & Farm \\
\hline Class5 & & 430 & 506 & 450.96 & 5.95 & 201,614 & \\
\hline Class6 & & 437 & 487 & 470.82 & 6.02 & 130,244 & \\
\hline Class7 & & 476 & 1092 & 522.88 & 45.54 & 208,573 & \\
\hline
\end{tabular}

output, partitioning the classified image into regions of connected pixels that are contained in the same class. This produces a new and more meaningful output, which can facilitate the image interpretation.

The segmentation process can be manipulated by the following three parameters: (i) colour, (ii) form and (iii) scale. The joint use of these three parameters enables us to obtain a segmentation of the classes already obtained from the classification step.

The first parameter balances the homogeneity of segment colour and shape. For the sake of example, the value "one" on the colour side will result in very fractal segments with a low standard deviation for pixel values, whereas a zero colour value would result in very compact segments with higher colour heterogeneity. In this paper we applied segmentation to the results of the classification and, therefore, the colour is actually the class to which the pixel belongs.

The scale parameter is an abstract value with no direct correlation to the object size, and it depends, rather, on the heterogeneity of the data. In our analysis, it is performed setting: $i)$ the minimum number of pixels to be considered in a region for building a segment, and ii) the number of neighbouring pixels which determines the separability/connectivity of the segments. We assumed the following values of $\mathrm{i}$ ) and ii) equal to 200 and 4 , respectively.

Finally, the form parameter controls the form features of an object by simultaneously balancing the criteria for smoothness of the object border and the criteria for object compactness. In this paper we focus on linear and rectangular shapes since the main interest of our investigations is the detection of geometric shape features (villas, aqueducts, etc.). Moreover, the shape indicator is set in a very simply way considering the ratio between the area and the perimeter of the given segment. This choice is made considering the specificity of an archaeological target. In other words, it is expected that the classification will be affected by the presence of scattered material, and therefore, the application of traditional segmentation algorithms to search for well defined rectangular polygons may provide not well segmented areas in most cases. To cope with this issue we used a simple criterion to search for the most elongated shape (roads, villas, aqueducts, etc.). This choice is not restrictive because the same procedure may be carried out considering (i) a more refined shape detector, or (ii) different expected geometrical patterns.

\section{Results from QuickBird-2 image processing and analysis}

The satellite data set used for this study is made up of two QuickBird images (panchromatic and multispectral bands), acquired with $0 \%$ percentage of cloud cover, on 25th March 2005 at 9:00 am and 10th
April 2007 at 9:20 am, respectively. The multispectral bands were pansharpened with the panchromatic band by using the Gram-Schmidt fusion method (Laben, 2000).

Due to the absence of significant vegetation cover and to the presence of microrelief (shadow-marks) and soil-marks, the classification and feature extraction was performed using panchromatic and red pan-sharpened scenes. The choice has been made because the highest spectral separability of shadow and soil marks has been observed using the panchromatic and red band, respectively (see Fig. 3). The feature extraction approach was applied twice at a global and a local scale (the results are shown in Figs. 4-6). In other words, global application indicates that the whole image was processed in order to detect anomalies of archaeological interest, whereas 'local' means that the procedure was applied to subsets centred on the previously detected anomalies in order to refine the features of archaeological interest. It is important to note that the interpretation of the results from ISODATA was made on the basis of the information already known for the archaeological remains in ROI A (see Fig. 1).

Features of archaeological interest belong to the yellow class, considering both panchromatic and red-pansharpened scenes (as shown in Figs. $4 c$ and d, 5c and d) along with other quite vast areas which were further processed with segmentation to isolate the (linear and quadrangular) geometric pattern area deemed to be of archaeological interest.

As an example, Table 1 shows the Global ISODATA statistics applied to the 2005 panchromatic image, related to the subset of Fig. 4.

Results from global classification and segmentation, applied to the 2005 and 2007 whole images, for ROI A (see Fig. 1) are shown in Figs. 4 and 5 respectively. Comparing the 2005 and 2007 panchromatic and red-pansharpened data (Figs. 4a-b and 5a-b), we notice a better visibility of archaeological microrelief in the 2005 scenes which highlighted a quadrangular shape anomaly referable to a buried building (see Figs. 4a,b and 5a,b, inside the green box). As expected (see Lasaponara \& Masini, 2007 and histograms of SSI in Fig. 3), in the 2005 scenes, the microreliefs are more visible from the panchromatic than in the redpansharpened scene. This fits well with the results obtained from the classification step (Fig. 4c-d) and the subsequent segmentation (Figs. 4, 5e-f). In detail, Fig. 4c and e clearly show the quadrangular pattern obtained by classification (yellow class) and segmentation (brown class) against its surroundings which had different characteristics. On the contrary, the feature extraction of red-pansharpened scenes (Fig. $4 \mathrm{~d}, \mathrm{f}$ ) produces a weaker outline than the above-mentioned quadrangular pattern from the classification product (Fig. 4d) and its total absence in the segmentation result (Fig. 4f).

In the 2007 scenes (Fig. 5a-b), the quadrangular anomaly is less evident with respect to its surrounding especially in the red pansharpened image (Fig. 5b). This is probably due to different local superficial conditions mainly surface moisture content. In fact, no land use changes occurred between the two images, but considering the subtle nature of archaeological features, weather conditions prior the image acquisition can have significant impact on their visibility.

As expected, we obtained a weaker performance from the feature extraction (Fig. 5c-f) for this subset. Specifically, the classification of panchromatic image categorizes the areas in the same class as in the 2005 imagery, but the segmentation is unable to isolate the anomaly from its surrounding (see green box in Fig. 5c,e). Finally, the classification and the segmentation of the 2007 red-pansharpened image does not provide any meaningful results (Fig. $5 \mathrm{~d}, \mathrm{f}$ ).

The other investigated area, within ROI A, shows the presence of linear soil-marks (see red box in Figs. 4a-b and 5a-b), probably associated with an aqueduct (as subsequently confirmed by the geophysical prospections). This area was processed using the same feature extraction approach (Figs. 4c-f and 5c-f). The best results, in terms of class discriminability, were obtained by processing the 2007 red pansharpened image (Fig. 5d,f). A weaker ability to discriminate using feature extraction was observed for the 2007 panchromatic scene and for both panchromatic and red pansharpened scenes in 2005. 
Passing from the global to the local scale, the segmentation of the unsupervised classification (see Fig. 6) provides fine details of the classes for the farm previously extracted from the global application (indicated by white arrows in Fig. 6). Moreover, additional features of possible archaeological interest (indicated by red arrows) were identified along with others relating to small country lanes still in use today (indicated by green arrows).

It is important to note that, in the local classification, features of archaeological interest are split into two classes (shown as yellow and blue in Fig. 6c), so the segmentation was made to take both of them in to account; thus merging and isolating them with the features of interest on the basis of their geometric pattern (see Fig. 6d).
The field survey performed on this area highlighted the presence of a farm dating from the early Imperial Roman age to the early Byzantine period. This chronology is based on the presence of fragments of tiles and pottery from these periods. It was also possible to find a few travertine blocks on the ground and some micro-relief anomalies probably due to the presence of buried walls.

In ROI B, the results from the feature extraction procedure applied at global scale to the 2005 red-pan-sharpened image highlighted another quadrangular shape pattern related to soil-marks. These relate to the perimeter of another farm (see Fig. 7, upper box), dating from the early Imperial Roman and the proto-Byzantine age, already known because of their discovery in 2008 by satellite remote sensing and field

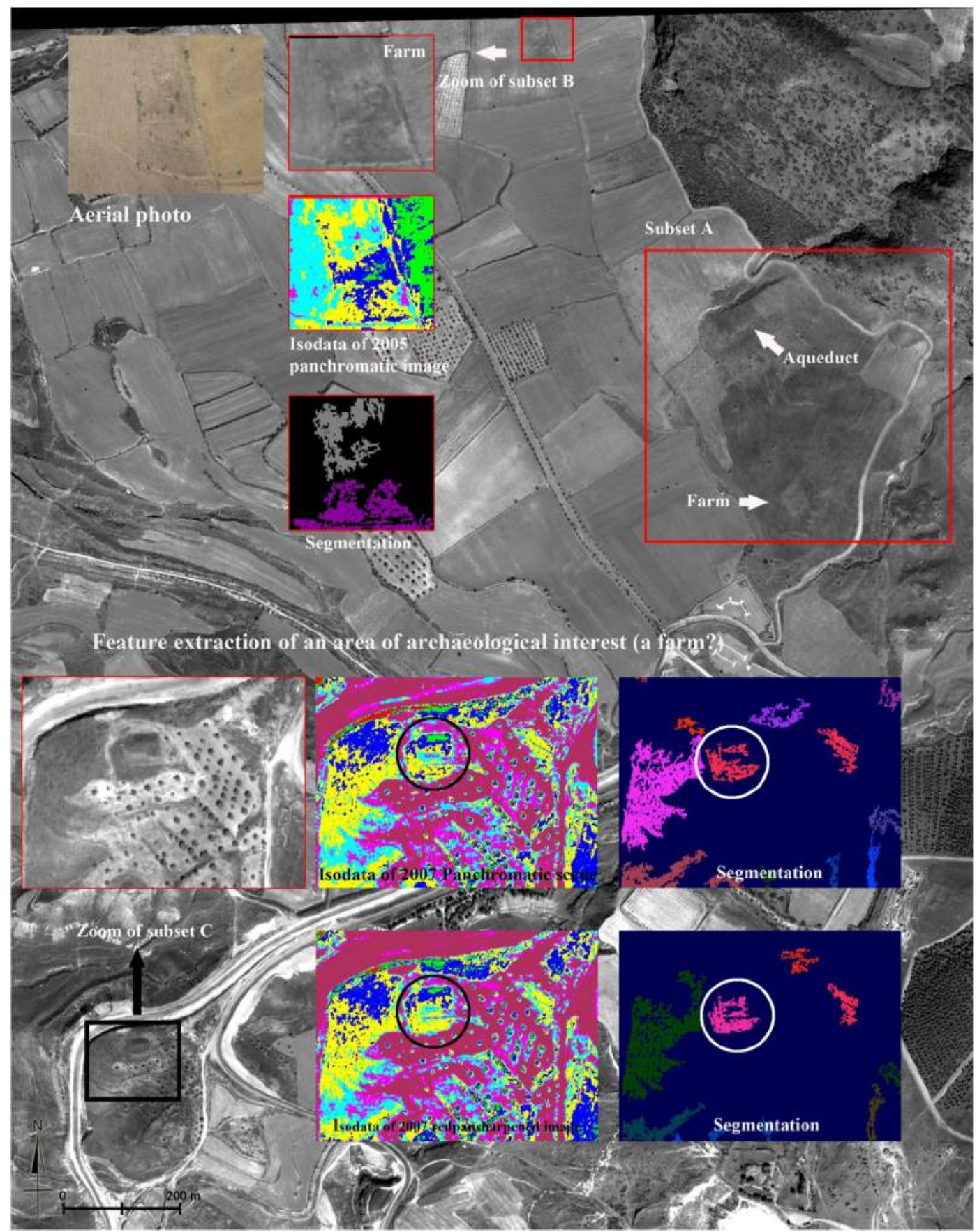

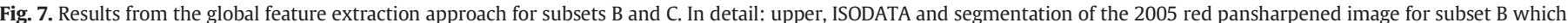

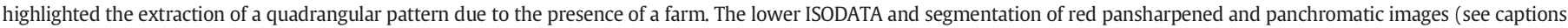

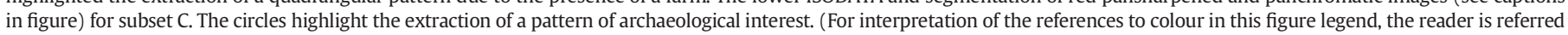
to the web version of this article.) 
survey (Lasaponara \& Masini, 2007). The extraction of this feature confirms the effectiveness of the approach proposed in this paper.

Finally, global feature extraction revealed an unknown archaeological pattern in ROI C (Fig. 7). Subsequent surveys confirmed the archaeological interest of this area, which is characterized by material fragments of tile, pottery, and stones of collapsed walls and foundations.

\section{Validation of satellite based results by geophysical investigations}

On the basis of the results obtained from the satellite data processing and field survey, some geophysical investigations were performed in ROI A with the aim of improving knowledge of the identified archaeological features with a view to future excavations (see Fig. 8).

Geomagnetic prospection was performed around the linear feature, thought to be linked to an aqueduct, in order to cover as large an area as possible, considering that the geomagnetic technique is less time consuming compared with other geophysical methods. In the case of the quadrangular anomaly, thought to be a Hellenistic and Roman farm, we conducted ground penetrating radar (GPR) investigations to ascertain the presence in a vertical section of buried structures in view of future trial excavations.

\subsection{GPR data acquisition and processing}

Many studies and investigations have demonstrated the highly significant role of GPR in searching for ancient buried remains (Conyers, 2004; Goodman \& Piro, 2013). The GPR prospecting was carried out using an IDS Hi Mod system with a $600 \mathrm{MHz}$ antenna. Data were acquired in continuous mode along $0.5 \mathrm{~m}$-spaced survey lines, using 512 samples per trace, an 80 ns time range, and a manual time-varying gain function.

The data were subsequently processed using standard twodimensional processing techniques (Persico, 2014) adopting GPR-Slice 7.0 software (Goodman, 2013). The processing flow-chart consisted of the following steps: i) header editing to insert the geometrical information, ii) frequency filtering, iii) manual gain, to adjust the acquisition gain function and enhance the visibility of deeper anomalies, iv) customized background removal to attenuate the horizontal banding in the deeper part of the sections (ringing), performed by subtracting a 'local' average noise trace in different time ranges estimated from suitably selected time-distance windows with low signal content (this local subtraction procedure was necessary to avoid artefacts created by the classic subtraction of a 'global' average trace estimated from the entire section, due to the presence of zones with a very strong signal), v) estimation of the average electromagnetic wave velocity by hyperbola fitting, and vi) Kirchhoff migration, using a constant average velocity value of $0.07 \mathrm{~m} / \mathrm{ns}$. The migrated data were subsequently merged together into three-dimensional volumes and visualized in various ways in order to enhance the spatial correlations of anomalies of interest.

One way to obtain visually useful maps for understanding the plan distribution of reflection amplitudes within specific time intervals is the creation of horizontal time slices. These are maps on which the reflection amplitudes have been projected at a specified time (or depth), with a selected time interval (Conyers, 2006). In a graphic method developed by Goodman et al. (2006), named "overlay analysis", the strongest and weakest reflectors at the depth of each slice are assigned specific colours. This technique allows linkage of structures buried at different depths. This allows an improvement in the imaging because

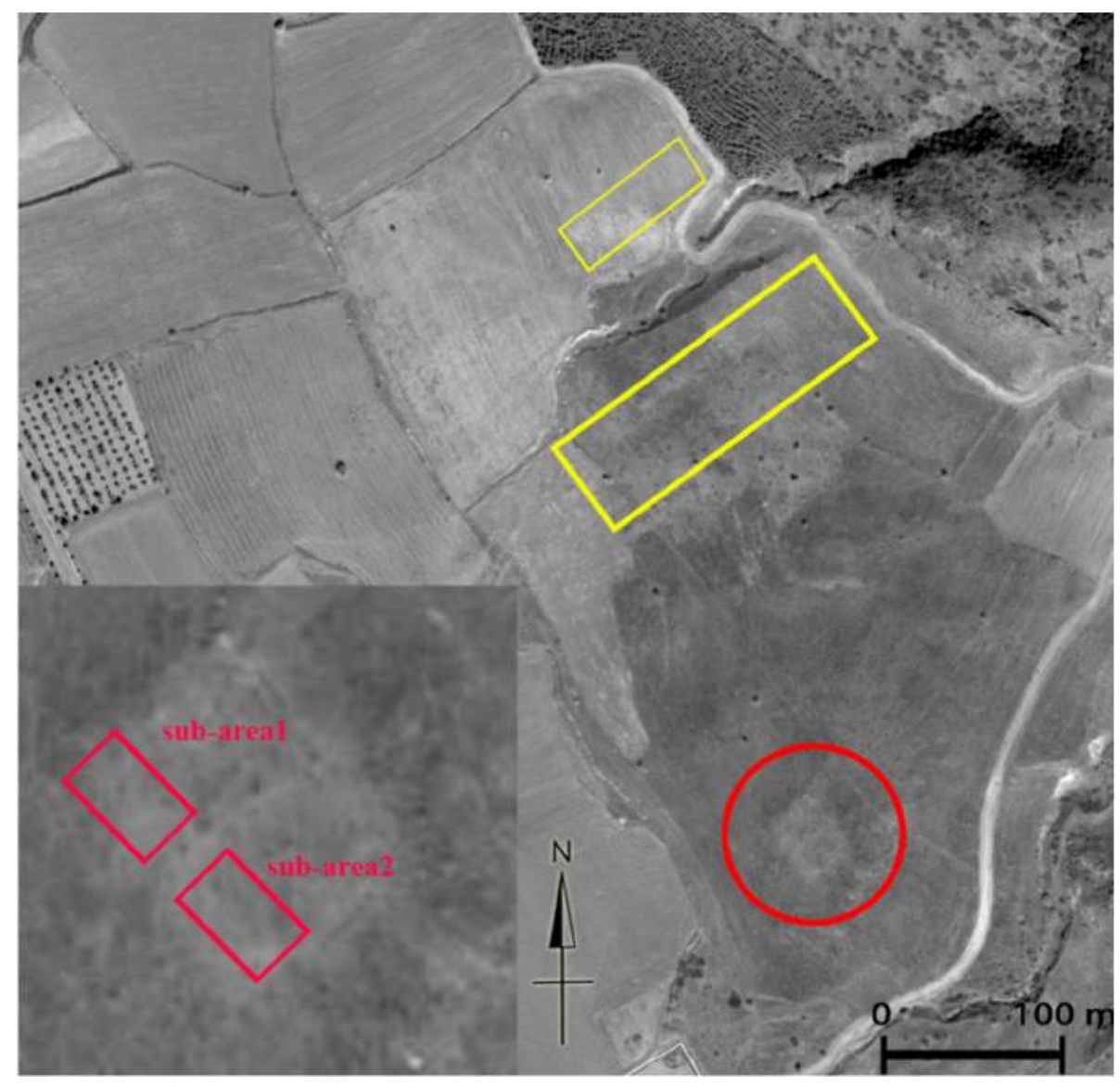

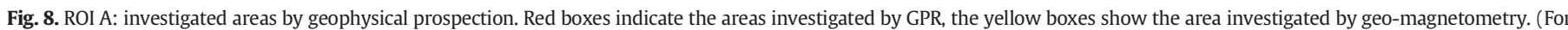
interpretation of the references to colour in this figure legend, the reader is referred to the web version of this article.) 
subtle features indistinguishable in the radargrams can be seen and interpreted more easily. In the present work, the time slice technique was used to display the amplitude variations within consecutive time windows with a width of $\Delta \mathrm{t}=5 \mathrm{~ns}$.

The surveyed area is inside the perimeter walls of the ancient farm (see Fig. 8 lower box) and was divided into two sub-areas of $7 \times 12 \mathrm{~m}$ and $7 \times 14 \mathrm{~m}$. The GPR system used a wheel odometer and was employed in continuous acquisition mode. The resulting spatial step of the data was $1.6 \mathrm{~cm}$. The ground surface was irregular and the surveyed areas were limited due to the presence of some obstacles (stones and plants). A general characteristic of the surveyed area was the good penetration depth of the electromagnetic energy, which can be estimated at $2.5 \mathrm{~m}$ (corresponding to the maximum recorded time of $70 \mathrm{~ns}$ ). Fig. 9 shows one of the GPR processed radar sections. In particular, the yellow circle (see Fig. 9) indicates the presence of a local reflection clearly referable to a wall featured by radar acquisition performed for sub-area 1 in ROI A. This is very important because it confirms the reliability of the satellite based data processing based on unsupervised classification that can only be evaluated using independent data set as herein performed. Moreover, since the GPR is an active sensor it also enables us to have information on the depth of the wall.

In Figs. 10-11 we present the depth slices, built by averaging the amplitudes of the processed data, within consecutive time windows with a width of $\Delta t=5 \mathrm{~ns}$. The spatial averaging along the depth can be useful to reduce small-scale heterogeneities and to mitigate some possible spike noise.

Lastly, the data were interpolated and gridded on a regular mesh. The interval $\Delta t$ has been chosen, as customary, equal to the period of the central harmonic component, of the band of the antennas. In the case at hand, the nominal central frequency is $600 \mathrm{MHz}$, but we have seen from the data that the actual central frequency is slightly lower than the nominal one, as customarily happens when the antennas work on the air-soil interface, especially for low values for the propagation velocity of the electromagnetic waves in the soil (as in the case at hand). From the depth slices, it is possible to observe several meaningful anomalies ascribable to buried structures (for additional details see Section 5).

GPR, being an active sensor, enables us to have information on the depth of the wall. Therefore, herein the use of GPR is two fold: (i) firstly to assess the reliability of satellite based classification and (ii) secondly to improve the information from the classification being that a satellite cannot provide any information relating to the depth of the anomalies since it is not able to penetrate the soil like other passive sensors. As a whole, from georadar prospection we were able i) to confirm the presence of buried remains and ii) to detail and characterize these archaeological features at the subsoil level (3D dimension) as well as to define the local stratigraphy, that according to Figs. 9, 10 and 11 is quite homogenous and only the anomaly related to the buried wall is evident.

\subsection{Magnetic data acquisition and processing}

The geomagnetic technique is considered the most suitable geophysical tool for archaeological research because of its reliability and its suitability to provide a fast magnetic image with high resolution data (Aspinall, Gaffney, \& Schmidt, 2008).

The measurements were performed on two regular grids (the first one of $180 \times 60 \mathrm{~m}$ and the second one of $90 \times 70 \mathrm{~m}$ ) which were set in the north-west part of ROI A. Gradiometric measurements were acquired by employing one Geometrix G858 (sensitivity $0.05 \mathrm{nT}$ ) in a vertical configuration of duosensors. Data were acquired in bi-directional mode, along parallel profiles $0.5 \mathrm{~m}$ apart with a sampling rate of 10 data/s, obtaining a mean spatial resolution of $0.5 \mathrm{~m} \times 0.125 \mathrm{~m}$.

In Fig. 12 (left and right) the two processed magnetograms are displayed in grey tones, in the range -5 (black) to 5 (white) nT. The magnetic data for each surveyed area were visualized as 8-bit raster images, after creating regular grids using a Kriging interpolator with a linear variogram. Processing procedures were applied to reduce noisy contributions that commonly corrupt the archaeological signals and consequently their correct interpretation, increasing in this way the signal/noise ratio. The readability of the archaeological anomalies was further improved through digital image processing techniques. Processing procedures based on statistical criteria and implemented in userfriendly software were applied to each surveyed area, to reduce these unwelcome contributions. First, spikes were identified and flagged through a statistical comparison between data within properly chosen windows. To this end, the generalized extreme Studentized deviate method was used (Goodman, 2013). Once flagged, spikes were removed from the original data set. Then, striping effects were minimized setting each collected magnetic profile at zero mean. Finally, a routine based on a statistical procedure using a cross-correlation function corrected the zig-zag effect to improve the signal/noise ratio (Eder-Hinterleitner, Neubauer, \& Melichar, 1998; Scollar, Tabbagh, Hesse, \& Herzog, 1990).

Resampling, matrix smoothing, clipping, filtering and contrast stretching operations were applied after data processing to enhance magnetic anomalies which appeared aligned in a SW-NE direction. The linear morphology of these anomalies clearly suggests the presence of buried pipelines.

As a whole, from the magnetic survey we were able i) to confirm the presence of buried remains and ii) to detail and characterize these archaeological features in 2D dimensions at higher spatial resolution compared to the satellite-based map. These remains can be related to buried pipelines considering the shape and the size they exhibited.

\section{Archaeological surveys}

The field survey confirmed the archaeological interest of the anomalies identified by the remote sensing data. All three ROIs were

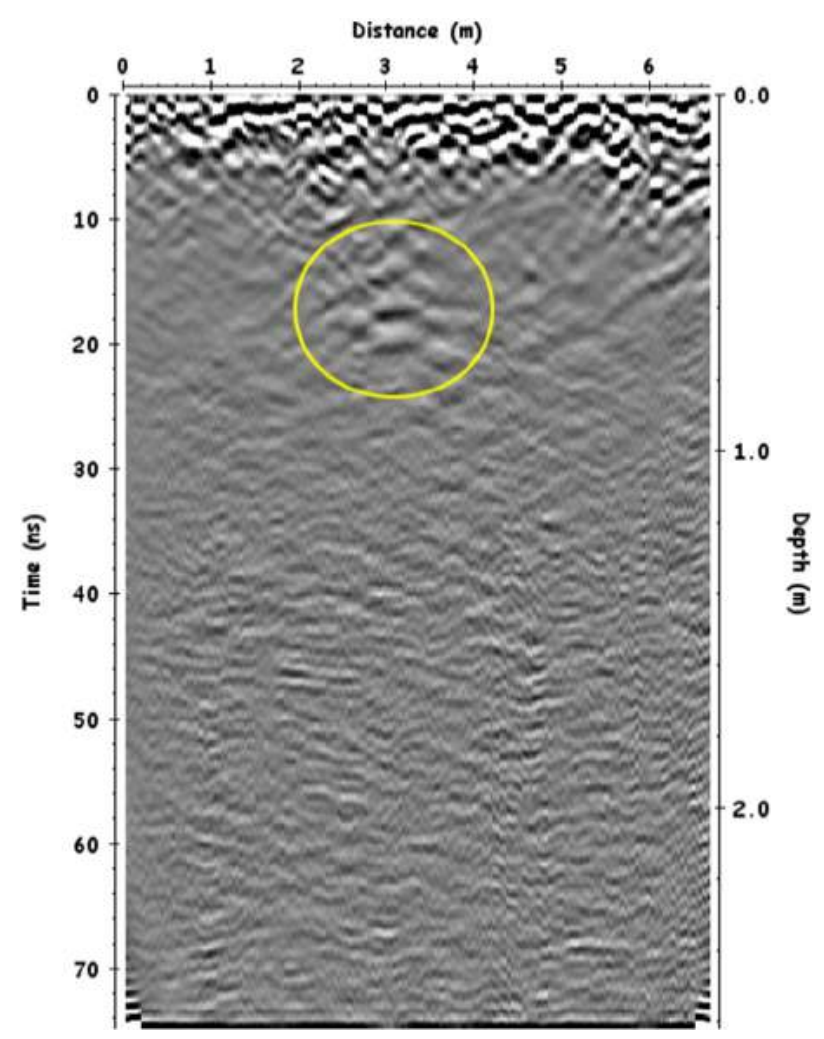

Fig. 9. Radar section from sub-area 1 in ROI A. Yellow circle indicates the presence of a local reflection clearly referable to a wall. (For interpretation of the references to colour in this figure legend, the reader is referred to the web version of this article.) 

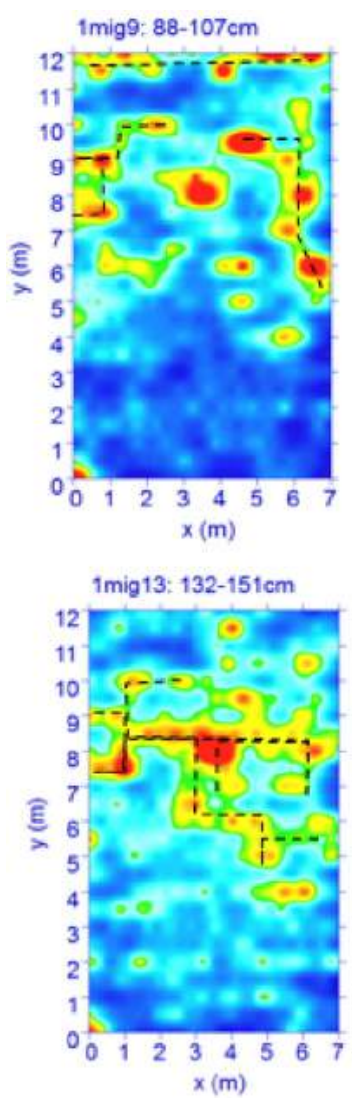
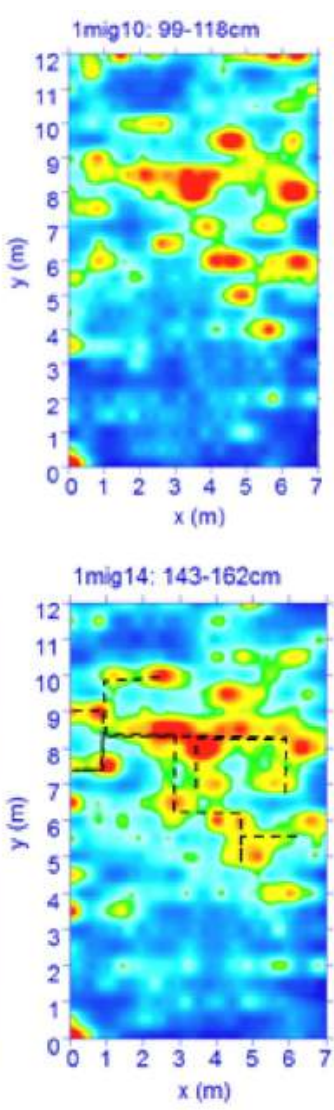
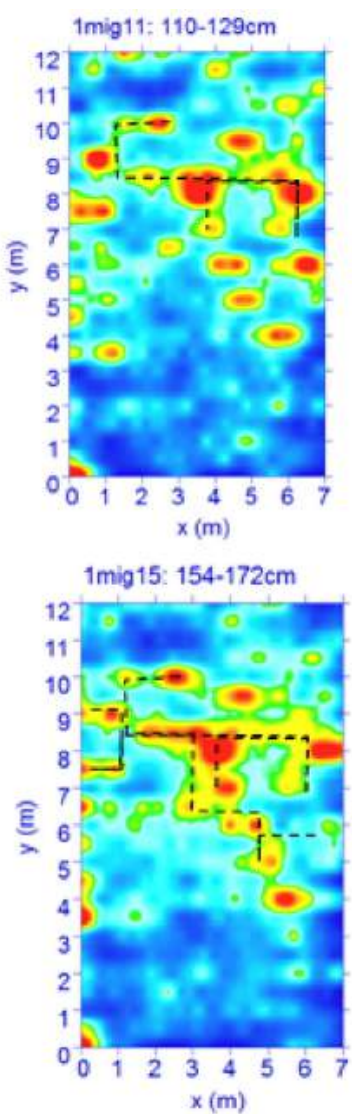

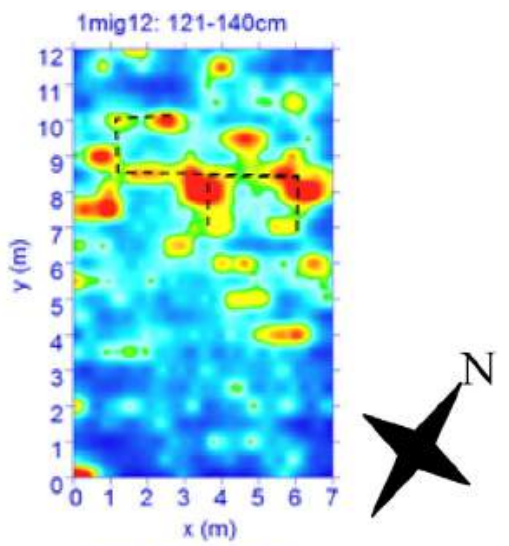

$1 \mathrm{mig} 16: 165-184 \mathrm{~cm}$

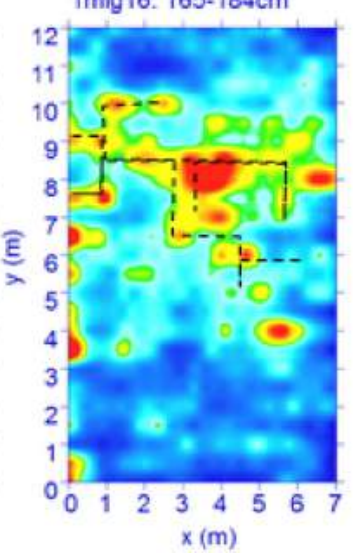

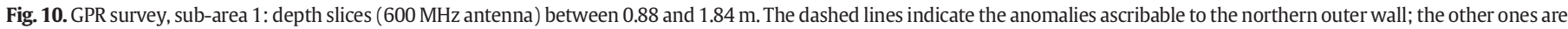
probably connected to internal structures of the building (see also Fig. 9).

characterized by the presence of fragments of travertine blocks, tiles and pottery (Fig. 13) that allowed us to date them between the Roman Imperial and the early Byzantine periods. It is worth pointing out that in ROI C we detected a pattern relating to a previously unknown farm.

In ROI A, the processed satellite images clearly show the fabric of the farm. The features which make up the building perimeter are the typical topographic micro-relief (shadow marks), whereas the internal divisions of the farm are provided by the remains of walls and foundations appearing on the surface for a few centimetres. To the south, on a terrace just below the rectangular farm, some stone materials aligned east-west are visible, thus confirming the archaeological interest of the extracted features from the local processing, as shown in Fig. 6d.

The GPR measurements allowed us to acquire interesting data on the internal structures to the western side of the building (Fig. 14). Several meaningful anomalies (nonevident from QuickBird scenes due to their pixel size) can be observed in the depth slices, starting from a depth of $0.4-0.5 \mathrm{~m}$. They can be ascribable to buried internal walls (visible at a depth of between 0.8 and $2.6 \mathrm{~m}$ in sub-areas 1 and 2) and to the northern outer wall (at a depth between 0.6 and $1 \mathrm{~m}$ in sub-area 1) of
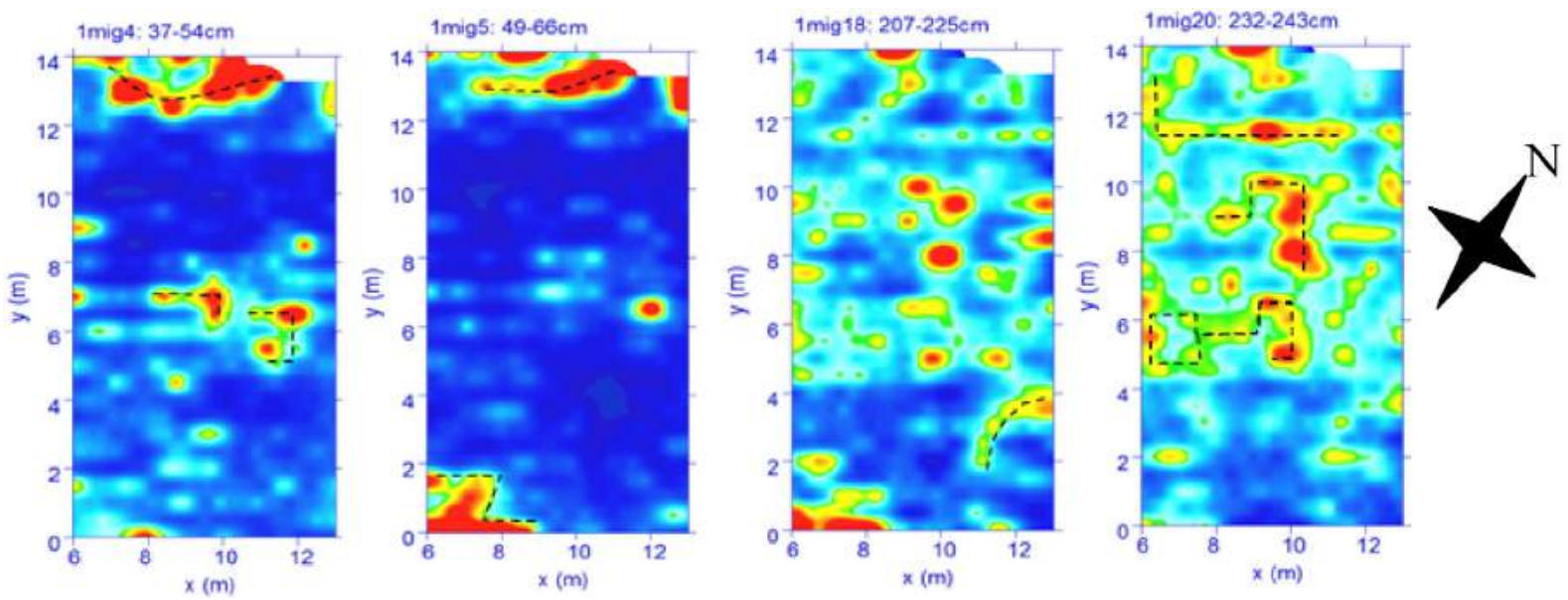

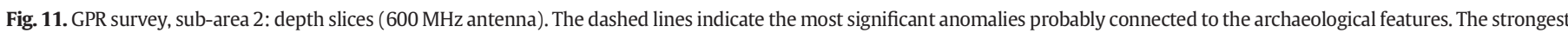
reflections could be observed at depths ranging from 2 to $2.40 \mathrm{~m}$. Their shapes suggest the presence of buried walls. 

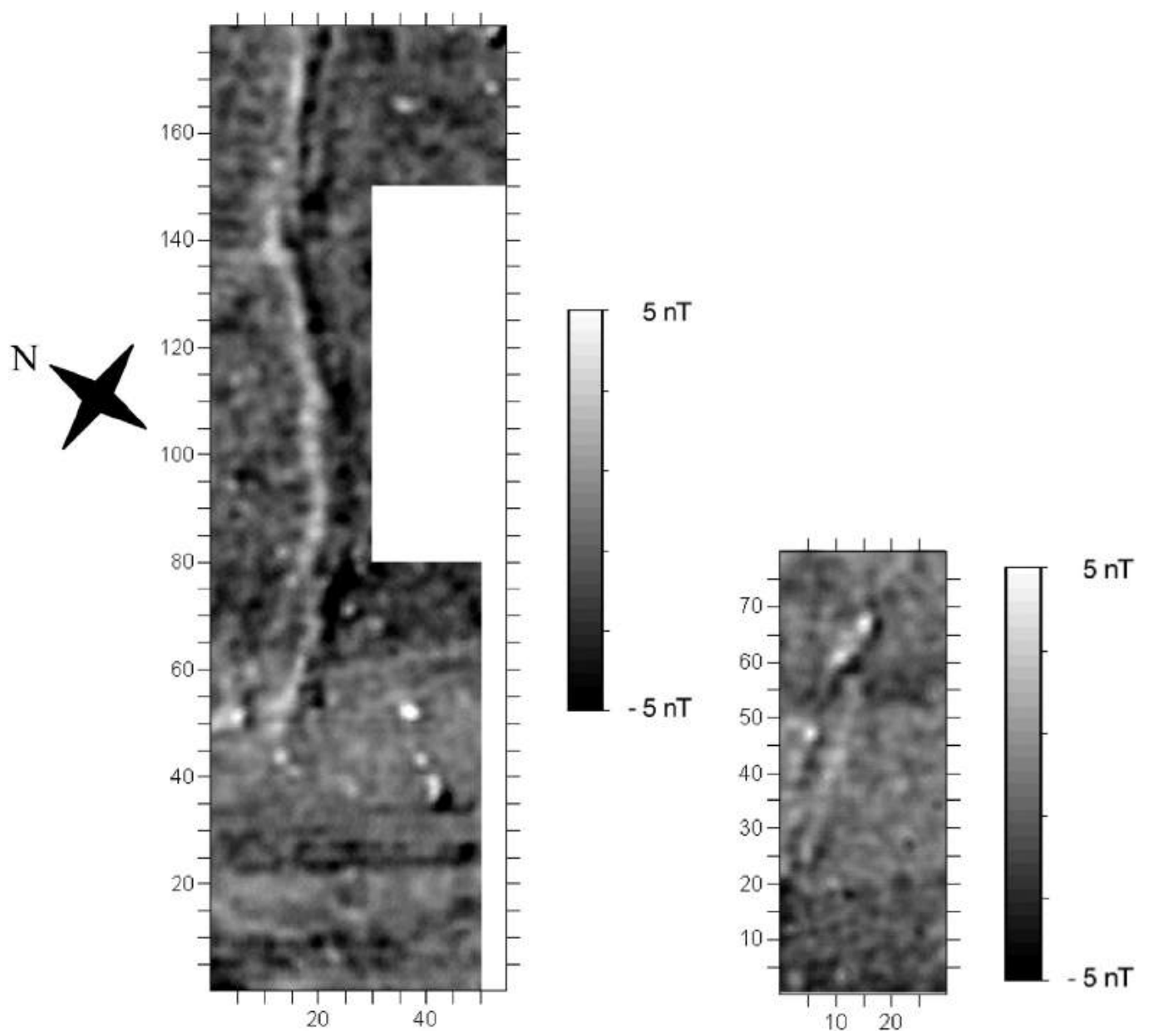

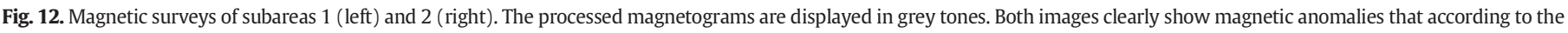
shape and size can be referable to pipe aqueducts.

the building. Finally, anomalies visible at the highest levels (depths of $0.3-0.5 \mathrm{~m}$ in sub-areas 1 and 2) can be attributed to structures from more recent times. The magnetic maps (see Figs. 12 and 15) clearly highlight some linear anomalies that are probably due to the presence of ancient buried pipelines (Fig. 15bc). Moreover, they can be attributed to pipelines on account of their dimensions and shapes; they can be related to pipelines, one pair on each side of the seasonal stream that divides the two surveyed areas. Archaeological surveys and trial excavations show that pipelines consist of pairs of $30-50 \mathrm{~cm}$ diameter terracotta pipes. (Fig. 15bc). These pipelines, buried in the earth or covered with stone slabs, brought water to the city in the Hellenistic, Roman and early Byzantine periods. They run along three main routes, between 6 and $13 \mathrm{~km}$ long, and transported drinking water from springs located immediately below the brow of the plateau to the north of the city. The pipelines evidenced by the magnetic measurements are part of an aqueduct system, some remains of which are partially preserved to the north-east of the surveyed areas (see $\mathrm{C}$ in Fig. 15a).
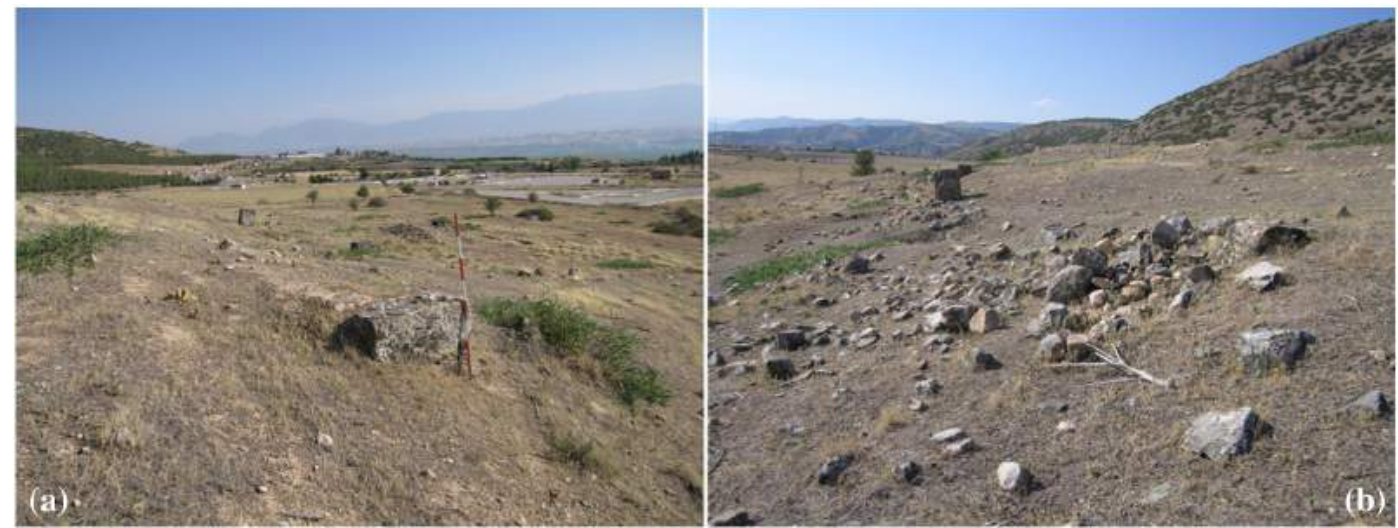

Fig. 13. Remains of the ancient farm in ROI A: views from south and north. 

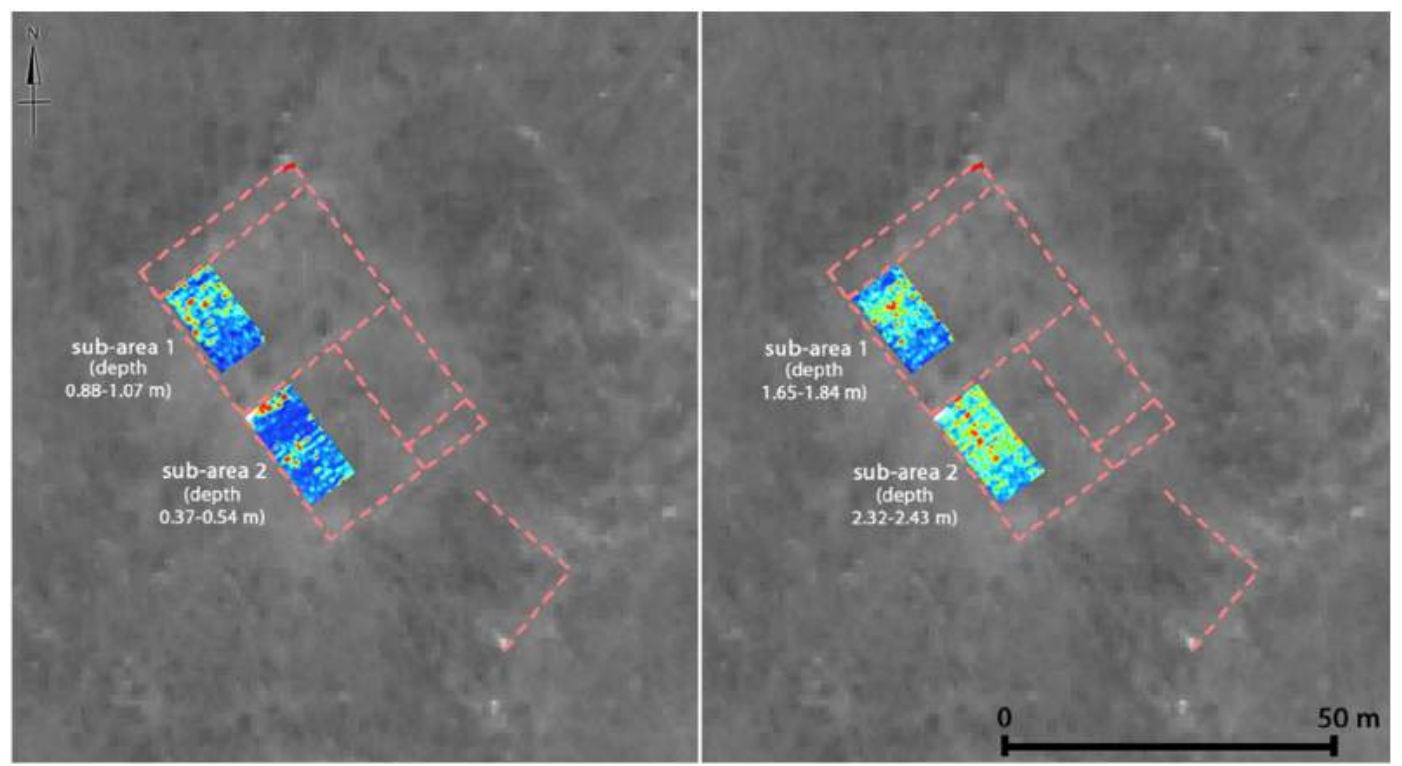

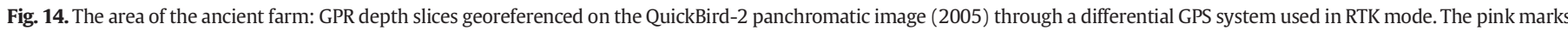
are derived from processed satellite data, while the slices show several meaningful anomalies that can be ascribable to the internal structures of the ancient settlement.

\section{Discussion of results}

This paper assesses the possibility of automatically extracting the subtle features/targets associated with archaeological buried remains.
In order to face the complexity of our aim, we adopted a data processing chain based on an object oriented approach that is applied twice: (i) firstly, globally at the whole image and, (ii) secondly, at the significant subsets identified by the global analysis, in order to refine the

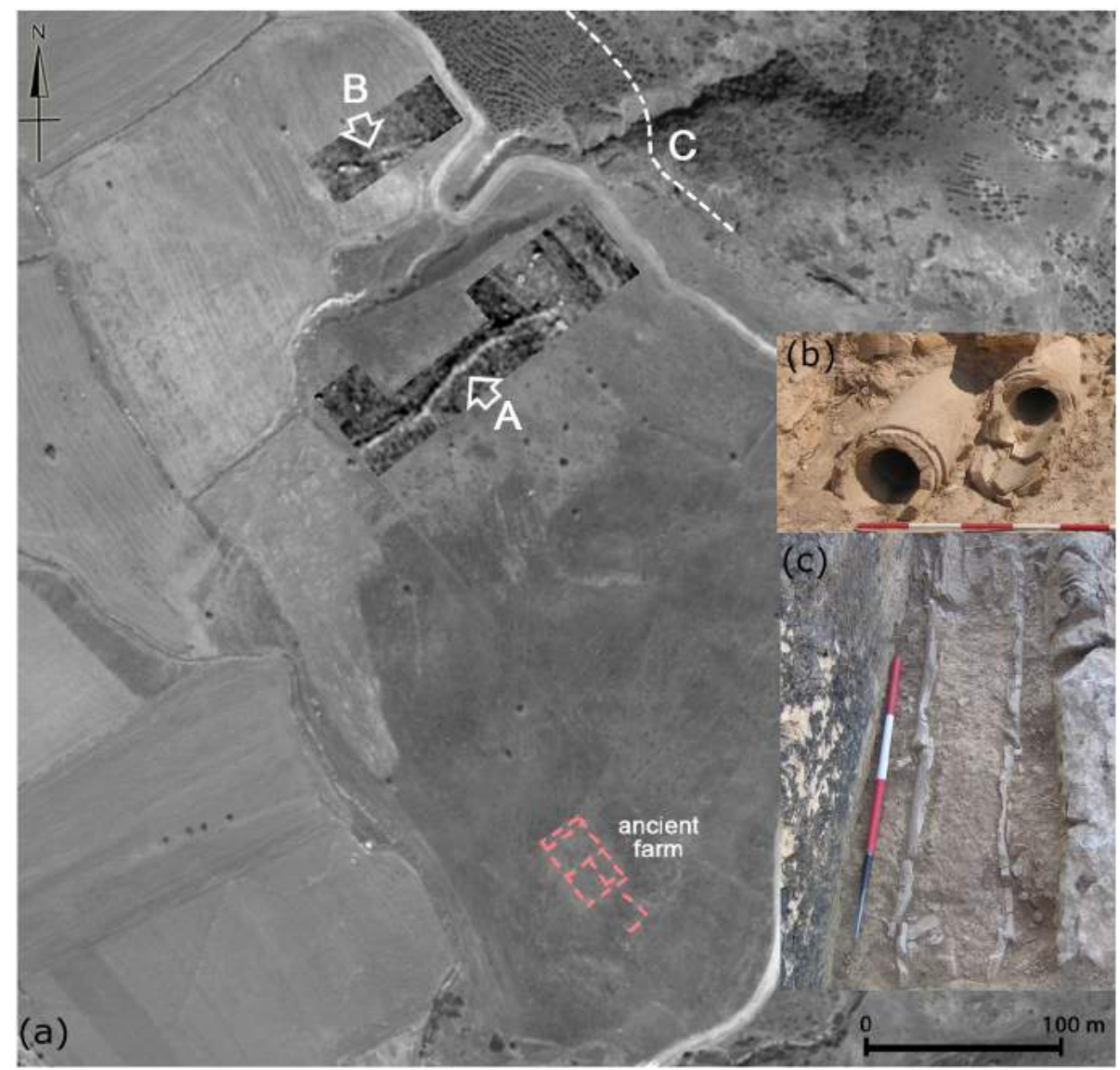

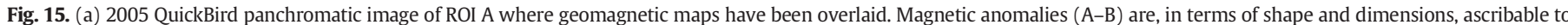

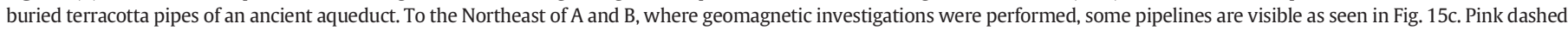

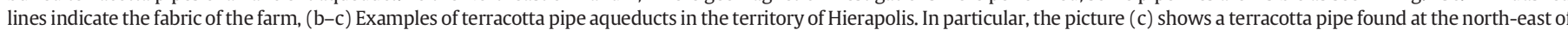
the surveyed areas. (For interpretation of the references to colour in this figure legend, the reader is referred to the web version of this article.) 
categorization previously obtained from global analysis. Moreover, an additional novelty of our methods is that instead of performing the segmentation and later the classification, as usual in object oriented approaches, herein, we firstly performed the unsupervised classification step and, then, the segmentation. This choice is given by the specificity of archaeological issue. In particular: (i) the subtle features to be identified are partially or totally unknown and characterized by a very small spectral separability from the background, therefore (ii) the discrimination between archaeological class and substrates likely suffers significant confusion which is reduced by exploiting the geometrical shape of the patterns (in the current case linear and rectangular).

The study was carried out in the archaeological Greek/Roman/ Byzantine site of Hierapolis (Turkey). It is a bare area, characterized by a significant presence of stones and scattered material that makes the investigation particularly complex. The aim of this test is to make this approach suitable for preventive archaeology and for planning archaeological excavations.

In three regions of interest, the approach proved able to extract three patterns of archaeological interest, among which one was previously unknown (ROI C), dating back to a historical period spanning from the Hellenistic to Byzantine ages, as confirmed by the field survey. Some unknown features relating to some sectors of an aqueduct were detected inside a known area of archaeological interest (ROI A). The geophysical prospection and field surveys allowed us to confirm the presence of two buried pipelines and to define the stratigraphy of the known farm dating to a historical period spanning from Imperial Roman to early Byzantine times.

Moreover, the results obtained clearly outline the effectiveness of the proposed approach, based on the use of multidate satellite images to cope with the expected large variability in the visibility of archaeological marks due to a change in superficial conditions (mainly moisture content). This is evident from the fact that the two high resolution satellite images yield considerably different results even if they were acquired from (i) the same sensor, (ii) in similar weather conditions (25 March, 2005 and 10 April 2007) and (iii) at the same time of the day (around 9:00-9:20 at the morning).

One of the strengths of this research is the demonstration, from the perspective of archaeologists, of the capability of satellite data to detect buried archaeological remains in an automatic way that is crucial, especially to exploit the invaluable data at high spatial resolution currently available from numerous satellite platforms.

\section{Conclusion and future perspectives}

The problem faced in this paper is the difficult exploitation of VHR satellite images for the identification and extraction of subtle signals which typically characterize shallow and buried archaeological remains. Another issue is given by the selection of satellite parameters to process (spectral channels, indices, band combinations, etc.), being that the archaeological features (and, in turn, their spectral characteristics) are unknown a priori. They depend on a number of variables linked to surface characteristics (desert, vegetated areas, crop phenology, etc.), soil properties, building materials (stone, rammed earth, adobe, etc.) and depths of archaeological remains.

To cope with these issues a feature extraction approach based on the use of unsupervised classification has been herein developed and applied to a typology of archaeological features whose proxy indicators are microrelief and soil marks. Such types of archaeological marks are easier to discriminate using panchromatic and red bands, as quantitatively evident by our previous work conducted in the same archaeological area.

Given the promising results in terms of extraction capability of features (linked to ancient rural farms of the territory of Hierapolis) this approach could be applicable to other areas and geographical regions with similar archaeological features, such as, for example, the medieval hilly settlements in Southern Europe or mounds and tells in Middle East which are visible from remote sensing by microrelief and macrorelief, respectively. Moreover, the procedure can be also be applied to aerial photographs, including historical archives and declassified satellite images, such as Corona, especially if available at high spatial resolutions as in the Middle East.

Among the key outcomes, our analysis highlights the following main evidences, satellite-based data and information which should be given support for having significant potential:

(i) plan time consuming and expensive archaeological excavations

(ii) preventive archaeology as an operative tool

(iii) help the decision makers in urban planning in areas and regions rich in cultural resources,

(iv) design strategies of modern infrastructures and buildings.

In the future the procedure will be applied to archaeological crop marks and to earthworks in arid desert settings located from Northern Africa to Southern America.

Finally, the procedure could also be applied to satellite SAR data considering their availability at very high resolution, as, for example, in the case of Cosmo SkyMed Spotlight and Terra SAR-X.

\section{Author contributions}

The authors cooperated in all the phases of the research and data processing and interpretation. G. Scardozzi coordinated the archaeological study; he is the author of Sections 2 and 7. G. Leucci processed the geomagnetic and GPR measurements and is the author of Section 6.2. R. Persico cooperated in the processing of the GPR data and is the author of Section 6.1. R. Lasaponara and N. Masini coordinated the whole study, processed the satellite images and are the authors of Sections 1, 3-5, and 8-9, and contributed to Section 6.

\section{Acknowledgements}

The authors wish to thank the anonymous referee who provided invaluable suggestions that enabled us to improve the paper.

\section{References}

Agapiou, A., \& Hadjimitsis, D.G. (2011). Vegetation indices and field spectroradiometric measurements for validation of buried architectural remains: Verification under area surveyed with geophysical campaigns. Journal of Applied Remote Sensing, 5(1), 053554.

Argote-Espino, D., \& Chavez, R.E. (2005). Detection of possible archaeological pathways in central Mexico through digital processing of remote sensing images. Archaeological Prospection, 12, 105-114.

Aspinall, A., Gaffney, C.F., \& Schmidt, A. (2008). Magnetometry for archaeologists. Lanham: AltaMira Press.

Ball, G.H., \& Hall, D.J. (1965). ISODATA, a novel method of data analysis and pattern classifcation. Menlo Park,United States: Stanford Research Institute (Office of Naval Research. Information Sciences Branch).

Beck, A.R. (2007). Archaeological site detection: The importance of contrast. Proceedings of the 2007 Annual Conference of the Remote Sensing and Photogrammetry Society. The Remote Sensing and Photogrammetry Society (Newcastle, 11-14 September 2007).

Conyers, L.B. (2004). Ground-penetrating radar for archaeology. Walnut Creek, California: Altamira Press.

Conyers, L.B. (2006). Innovative ground-penetrating radar methods for archaeological mapping. Archaeological Prospection, 13(2), 139-141.

Crawford, G.S. (1929). Air photography for archaeologists. Ordnance survey professional papers, new series, 12. Southampton: HMSO.

D'Andria, F., Scardozzi, G., \& Spanò, A. (2008). Atlante di Hierapolis di Frigia. Istanbul: Ege Yayınları.

De Laet, V., Paulissen, E., \& Waelkens, M. (2007). Methods for the extraction of archaeological features from very high-resolution Ikonos-2 remote sensing imagery, Hisar (southwest Turkey). Journal of Archaeological Science, 34, 830-841.

D'Orazio, T., Palumbo, F., \& Guaragnell, C. (2012). Archaeological trace extraction by a local directional active contour approach. Pattern Recognition, 45, 3427-3438.

Eder-Hinterleitner, A., Neubauer, W., \& Melichar, P. (1998). Restoring magnetic anomalies. Archaeological Prospection, 3, 185-197.

Figorito, B., \& Tarantino, E. (2014). Semi-automatic detection of linear archaeological traces from orthorectified aerial images. International Journal of Applied Earth Observation and Geoinformation, 26, 458-463. 
Garrison, T.G., Houston, T.G., Golden, C., Inomata, T., Nelson, Z., \& Munson, J. (2008). Evaluating the use of IKONOS satellite imagery in lowland Maya settlement archaeology. Journal of Archaeological Science, 35(10), 2770-2777.

Goodman, D. (2013). GPR Slice v 7.0 Manual. From http://www.gpr-survey.com

Goodman, D., \& Piro, S. (2013). GPR remote sensing in archaeology. Series: geotechnologies and the environment, Vol. 9. (pp. XI). Springer.

Goodman, D., Steinberg, J., Damiata, B., Nishimure, Y., Schneider, K., Hiromichi, H., \& Hisashi, N. (2006). GPR overlay analysis for archaeological prospection. Proceedings of the 11th International Conference on Ground Penetrating Radar, Columbus. Ohio USA: CD-rom.

Grøn, O., Palmèr, S., Stylegar, F. -A., Esbensen, K., Kucheryavski, S., \& Aase, S. (2011). Interpretation of archaeological small-scale features in spectral images. Journal of Archaeological Science, 38(9), 2024-2030.

Laben, E.A. (2000). Process for enhancing the spatial resolution of multispectral imagery using PAN-sharpening (Gram-Schmidt). available online at: http:// www.freepatentsonline.com/6011875 (2000)

Lasaponara, R., \& Masini, N. (2006). Identification of archaeological buried remains based on Normalized Difference Vegetation Index (NDVI) from Quickbird satellite data. IEEE Geoscience and Remote Sensing Letters, 3(3), 325-328.

Lasaponara, R., \& Masini, N. (2007). Detection of archaeological crop marks by using satellite QuickBird. Journal of Archaeological Science, 34, 214-221.

Lasaponara, R., \& Masini, N. (Eds.). (2012). Satellite remote sensing: A new tool for archaeology. Springer, Verlag Berlin Heidelberg.

Lasaponara, R., Leucci, G., Masini, N., \& Persico, R. (2014). Investigating archaeological looting using satellite images and georadar: The experience in Lambayeque in North Peru. Journal of Archaeological Science, 42, 216-230.

Lasaponara, R., Masini, N., \& Scardozzi, G. (2008). New perspectives for satellite-based archaeological research in the ancient territory of Hierapolis (Turkey). Advances in Geosciences, 19, 87-96.

Luo, L., Wang, X., Guo, H., Liu, C., Liu, J., Li, L., ... Qian, G. (2014). Automated extraction of the archaeological tops of Qanat Shafts from VHR imagery in Google Earth. Remote Sensing, 6(12), 11956-11976.

Masini, N., \& Lasaponara, R. (2006a). Satellite-based recognition of landscape archaeological features related to ancient human transformation. Journal of Geophysics and Engineering, 3, 230-235.

Masini, N., \& Lasaponara, R. (2006b). Evaluation of the spectral capability of Quickbird imagery for the detection of archaeological buried remains. In S. Campana, \& M. Forte (Eds.), Space to place, Proceedings of 2nd International Conference on Remote Sensing in Archaeology (Rome, December 4-7, 2006). BAR international series. (pp. 21-29).
Masini, N., Lasaponara, N., \& Orefici, G. (2009). Addressing the challenge of detecting archaeological adobe structures in Southern Peru using QuickBird imagery. Journal of Cultural Heritage, 10S, e3-e9.

Persico, R. (2014). Introduction to ground penetrating radar, inverse scattering and data processing. Wiley.

Rowlands, A., \& Sarris, A. (2007). Detection of exposed and subsurface archaeological remains using multi-sensor remote sensing. Journal of Archaeological Science, 34 795-803.

Scardozzi, G. (2011). Integrated methodologies and technologies for the reconstruction of the ancient topography of Hierapolis in Phrygia and its surrounding territory (Turkey). Proceedings of the 5th International Congress "Science and Technology for the Safeguard of Cultural Heritage in the Mediterranean Basin" (pp. 192-202). Rome: CNR ((Istanbul 22nd-25th November 2011).

Scardozzi, G. (2012). Ricognizioni archeologiche nel territorio di Hierapolis: gl acquedotti, le cave di materiali lapidei, gli insediamenti rurali, i tumuli funerari. In F. D'Andria, M.P. Caggia, \& T. Ismaelli (Eds.), Hierapolis di Frigia, V. Le attività delle campagne di scavo e restauro 2004-2006. Istanbul: Ege Yayınları.

Schuetter, J., Goel, P., McCorriston, J., Park, J., Senn, M., \& Harrower, M. (2013). Autodetection of ancient Arabian tombs in high-resolution satellite imagery. International Journal of Remote Sensing, 34, 6611-6635.

Scollar, I., Tabbagh, A., Hesse, A., \& Herzog, I. (1990). Archaeological prospecting and remote sensing. Cambridge: Cambridge University Press.

Tarantino, E., \& Figorito, B. (2014). Steerable filtering in interactive tracing of archaeological linear features using digital true colour aerial images. International Journal of Digital Earth, 7, 870-880.

Traviglia, A., \& Cottica, D. (2011). Remote sensing applications and archaeological research in the Northern Lagoon of Venice: The case of the lost settlement of Constanciacus. Journal of Archaeological Science, 38(9), 2040-2050.

Trier, Ø. D., Larsen, S.O \& Solberg, R. (2009). Automatic detection of circular structures in high-resolution satellite imagery of agricultural land. Archaeological Prospection, $16,1-11$.

Wilson, D.R. (1982). Air photo interpretation for archaeologists. London: St. Martin's Press.

Wonsok, K., Nie, Y., Zhu, J., Deng, B., Yu, L., Liu, F., \& Gao, H. (2013). Local orientation based detection of circular soil marks of ancient graves by GA. Journal of Remote Sensing, 17, 671-678. 